\title{
Mathematical Analysis of the Concomitance of Illicit Drug Use and Banditry in a Population
}

John Olajide Akanni ( $\sim$ jide28@gmail.com )

KolaDaisi University https://orcid.org/0000-0002-1343-345X

Afeez Abidemi

Federal University of Technology Akure

\section{Research Article}

Keywords: Illicit drug use and banditry model, Illicit drug use and banditry repro- duction number, Bifurcation analysis, Sensitivity analysis.

Posted Date: December 27th, 2021

DOI: https://doi.org/10.21203/rs.3.rs-1089919/v1

License: (1) This work is licensed under a Creative Commons Attribution 4.0 International License. Read Full License 


\title{
Mathematical analysis of the concomitance of illicit drug use and banditry in a population
}

\author{
Akanni, John O. ${ }^{1 *}$ and Abidemi Afeez ${ }^{2 \dagger}$ \\ Department of Pure and Applied Mathematics, Ladoke Akintola University of Technology, Ogbomoso, Oyo State, Nigeria \\ 2 Department of Mathematical Sciences, Federal University of Technology, Akure, P.M.B. 704, Ondo State, Nigeria
}

\begin{abstract}
One of the majors global health and social problem facing the world today is the use of illicit drug and the act banditry. The two problems have resulted into lost of precious lives, properties and even a devastating effects on the economy of some countries where such acts were been practiced. Of interest in this work is to study the global stability of illicit drug use spread dynamics with banditry compartment using a dynamical system theory approach. Illicit drug use and banditry reproduction number was evaluated analytically, which measures the potential spread of the illicit drug use and banditry in the population. The system exhibits supercritical bifurcation property, telling us that local stability of an illicit drug and banditry-present equilibrium exist and it is unique. In addition, the illicit drug and banditry-free and illicit drug and banditry-present equilibria were shown to be global asymptotically stable, this was achieved by construction of suitable Lyapunov functions. Sensitivity analysis was carried out to know the impact of each parameter on the dynamical spread of illicit drug use and banditry in a population. Numerical simulations were used to validate the obtained quantitative results, and examine the effects of some key parameters on the system. It was discovered that, to reduce the burden of banditry in the population, stringent control measures must be put in place to reduce the use of illicit drug in a population. Suggested control measures to use in curtail the menace of the illicit drug use and banditry were recommends.
\end{abstract}

Keywords: Illicit drug use and banditry model, Illicit drug use and banditry reproduction number, Bifurcation analysis, Sensitivity analysis.

\section{Introduction}

The world is facing many problem today, which can be classified as follows; "poverty, religious conflict, political polarization, government accountability (political scandals), education (access to schooling), food and water scarcity, poor health facilities in developing nations, lack of access to credit, discrimination, physical fitness" and the host others [1].

\footnotetext{
*Correspondence: jide28@gmail.com

†Correspondence: aabidemi@futa.edu.ng
} 
One of the element of poor health facilities and poverty is the use of illicit drug and banditry [2]. The production, abuse of illicit drug and act of banditry has increased sporadically in Africa, in the last decades [3]. This increase has impacted the costs on the public health system and also increased in the spread of other epidemics, such as HIV, Gonorrhea and the host of other sexually transmitted diseases[4]. Illicit drug use remains a serious problem; with countless number of health risks, increase in the rate of social vise and also jack-up the expenses of government $[4,5]$.

The term Illicit drug use also known as substance abuse was defined by Nutt et al. [6] as an excessive use of a drug or the mode of usage of drug which is detrimental to users or people around him / her. Some of the substance abuse among humans today is Marijuana; which is dehydrated leaves $[2,7,8,9,10]$. Marijuana is a dehydrated leaf which has a chemical components that alters mind and makes the consumers behave irrationally $[9,10,11,12]$. Alcohol is another type of substance abuse, which causes harm to health of the one that takes it $[9,13,14]$. When a pregnant woman takes alcohol, it has a great negative effect to the unborn baby (fetus), it can even cause miscarriage $[15,9]$.

According to $[15,16]$, the rates of methamphetamine consumption in the World today, particularly Africa is on high side. The population of those that use methamphetamine abnormally are youths $[9,17]$. The effect of illicit drug use are serious in African countries like South Africa, Nigeria and Ghana, the illicit drug use has a serious and great effect on their population particularly among their youth [15, 16]. SACENDU [18] report between January and June 2013; shows that $76 \%, 71 \%, 59 \%, 67 \%$ and $59 \%$ are of illicit drug use patients that were man, coloured people, jobless, single and between the ages of 15 and 29 years respectively. The population of illicit drug user varies from one place to another even in Africa, for example, the Western Cape Province has a high rate of illicit drug use consumption in comparison to some other provinces in South Africa [19, 20]. These province are the one causing trouble in South Africa, and the substance being abused are alcohol, methamphetamine and marijuana [21]. Also, Tik, is another substance abuse in Cape Town $[9,18]$.

Banditry can be defined as a type of organized crime committed by outlaws typically involving the threat or use of violence. A person who engages in banditry is known as a bandit [22]. According to [22] causes of banditry can be ecological and climate change, consistent shift in human and livestock populations, weak state capacity and the provision of security, proliferation of small arms and light weapon and the host of others. Examples of banditry are sexual assault of women and girls, theft, attacks on banks, market and school hostel, amongst others [10, 22].

Many researchers have used the ideal of mathematical modeling to provide solution to the problem of illicit drug use and banditry, either separately or together has a complex problem. Few of them are; Pang et al. [23] examined the effect of tobacco on a country being victimized by its consumptions, where China was the concerned country. It was noted that this country was seriously affected by smoking-associated sicknesses. The work major on the issue of curtailing smoking in China. Kalula and Nyabadza [24] aimed at the qualitative investigation of the dynamics of substance abuse and predicting drug abuse trends. The analysis of the model was presented in terms of the substance abuse epidemic threshold $\mathcal{R}_{0}$. Simulations were performed to fit the model to available data for methamphetamine use in the Western Cape, determine the role played by some key parameters and 
methamphetamine users who entered rehabilitation using the least squares curve fitting method. It is important to note that their model exhibits a backward bifurcation, pointing that it is not sufficient to reduce $\mathcal{R}_{0}$ below unity to control the substance abuse epidemic.

In the works of $[6,24]$, one of their findings is that the illicit drug use problem can be eradicated if light drug users are targeted with appropriate controls, and treatment rates for drug addicts are also beefed up. One of the problems associated with Methamphetamine drug use is abnormal desire for sex which may likely increase sexually transmitted infections (STIs) and HIV [25]. In [10], a study on substance abuse which used a mathematical model to gain an insight to the dynamics spread of drug abuse and banditry in a population was carried out. It is important to note that the study exhibits backward bifurcation, pointing that it is not only sufficient to lower the $\mathcal{R}_{0}$ below unity, but other things must be put into consideration. Also, sensitivity analysis was done to determine impart of parameters of the model on the spread of the drug abuse and banditry menace in the population.

This study take into account the concomitant of illicit drug use and banditry, the presence of relapse of illicit drug user and bandit and the quitters compartment which is less or not concerned in the existing literatures, the formed the major purpose of this work. Hence, a new mathematical model was used to explore the co-problematic population of illicit drug user and bandit, the presence of relapse illicit drug user and bandit and the quitters compartment. The rest of study is sectionalized in the following order: Section 2 is for the model formation and analysis of the basic properties. In Section 3, stability and sensitivity analyses of the illicit drug use and banditry model are carried out. Concluding remarks are given in Section 4.

\section{Model Formation}

The dynamics of the concomitant of illicit drug use and banditry (IDUB) in the population was considered with the total population denoted by $N(t)$, at time $t$, which was sub-divided into seven well-defined classes, susceptible individuals $S(t)$ (those who are in the company of illicit drug user or/and bandit but who are neither illicit drug user nor bandit), Illicit drug user $I(t)$ (someone who abuse drug or those who absolutely depends on drugs wrongly), suspected bandit $B(t)$ (someone who commit banditry or involve in bandit act), detainee $D(t)$ (illicit drug user or/and suspected bandit who are in police custody), Prisoner $P(t)$ (illicit drug user or/and suspected bandit that was imprison) and rehabilitation population $R(t)$ (illicit drug user or/and bandit who are undergoing rehabilitation) and quitters $Q(t)$ (illicit drug user or/and bandit who quit this or these act). The population is not a constant population size because the recruitment (births) is not balanced by removal (natural deaths) rates due to induced death rate $\delta$. Figure 1 represents the schematic diagram for the concomitant of illicit drug use and banditry population dynamics, which the nonlinear ordinary differential equations (1) is the governed system. 


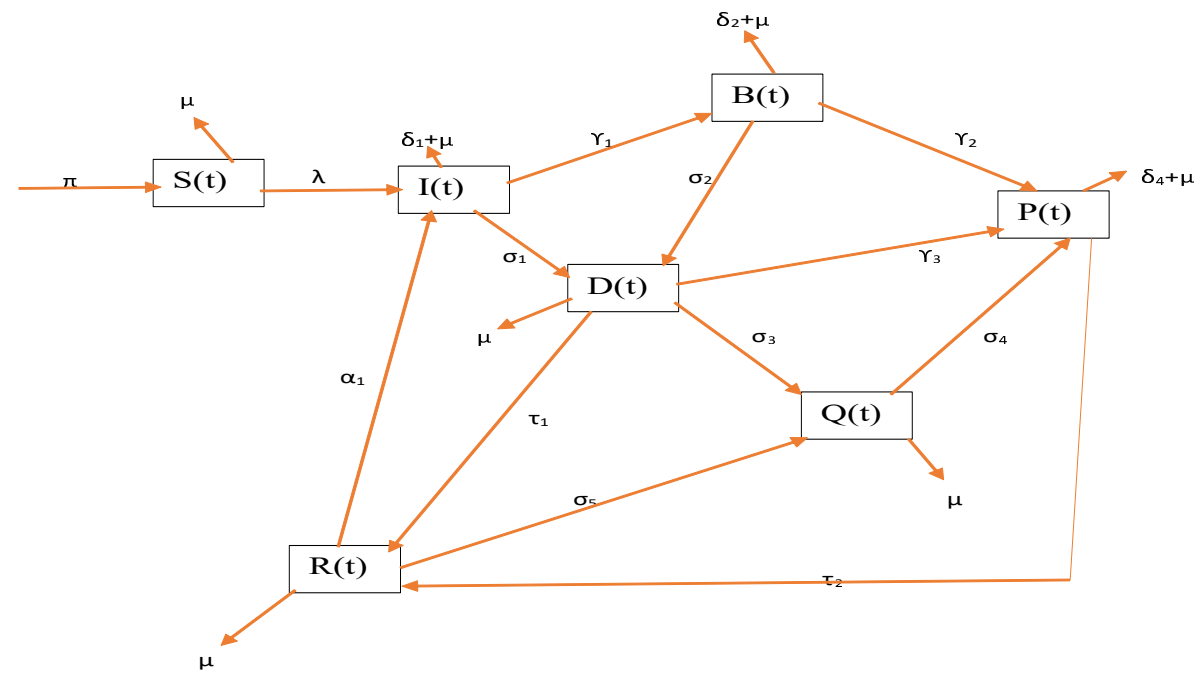

Figure 1: Schematic diagram of the model (1)

$$
\begin{aligned}
& \frac{d S}{d t}=\pi-\beta \frac{I(t)+\eta B(t)}{N(t)} S(t)-\mu S(t) \\
& \frac{d I}{d t}=\beta \frac{I(t)+\eta B(t)}{N(t)} S(t)+\alpha_{1} R(t)-\left(\sigma_{1}+\gamma_{1}+\delta_{1}+\mu\right) I(t) \\
& \frac{d B}{d t}=\gamma_{1} I(t)-\left(\sigma_{2}+\gamma_{2}+\delta_{2}+\mu\right) B(t) \\
& \frac{d D}{d t}=\sigma_{1} I(t)+\sigma_{2} B(t)-\left(\sigma_{3}+\gamma_{3}+\tau_{1}+\mu\right) D(t) \\
& \frac{d P}{d t}=\gamma_{2} B(t)+\gamma_{3} D(t)-\left(\sigma_{4}+\tau_{2}+\delta_{4}+\mu\right) P(t) \\
& \frac{d R}{d t}=\tau_{1} D(t)+\tau_{2} P(t)-\left(\sigma_{5}+\alpha_{1}+\mu\right) R(t) \\
& \frac{d Q}{d t}=\sigma_{3} D(t)+\sigma_{4} P(t)+\sigma_{5} R(t)-\mu Q(t),
\end{aligned}
$$

with initial conditions when $t=0$ :

$$
S(0)=S_{0}, B(0)=B_{0}, I(0)=I_{0}, D(0)=D_{0}, P(0)=P_{0}, R(0)=R_{0}, Q(0)=Q_{0} .
$$

The following assumptions guide the dynamics of the model been formulated : the interaction of susceptible humans with illicit drug users and bandits first results into illicit drug users then progresses to bandit population thereafter. Also, rehabilitated individuals moves back to illicit drug users due to one reason or the other during treatment. Furthermore, the illicit drug users and bandit populations moved to detention before being 
transfered to prison. Moreover, the detainees can either move to prison or rehabilitation center. In summary, the illicit drug use and banditry model is given by the system of nonlinear ordinary differential equations (1) with the nonnegative initial conditions (2) and the schematic diagram represented by Figure 1. For limpidity, the definition of variables and parameters used in model (1) are given in Table 1.

Looking through the system of equation (1), one can notice that (Q) only appear in the last equation of system; on this note, for theoretical analysis, the (Q) compartment of system (1) will be silence [26].

The equation of the total population which is obtained by adding all the equations of (1) is given below:

$$
\frac{d N}{d t} \leq \pi-\mu N
$$

Table 1. Definition of variables and parameters

\begin{tabular}{cl}
\hline \hline Variable/Parameter & Definition \\
\hline \hline$S(t)$ & susceptible individuals \\
$I(t)$ & illicit drug users \\
$D(t)$ & suspected bandits \\
$P(t)$ & detainees \\
$R(t)$ & prisoners \\
$Q(t)$ & rehabilitate individual \\
$\pi$ & quitters \\
$\alpha_{1}$ & movement of rehabilitate to illicit drug user \\
$\eta$ & modification parameter for suspected bandits \\
$\sigma_{1}$ & detention rate of illicit drug users \\
$\gamma_{1}$ & progression rate of illicit drug users to suspected bandits \\
$\delta_{1}$ & induce death rate of illicit drug users \\
$\beta$ & effective influence rate \\
$\delta_{4}$ & induce death rate of those in prisoners \\
$\mu$ & natural rate \\
$\sigma_{2}$ & detention rate of suspected bandits \\
$\gamma_{2}$ & movement of suspected bandits to prisoners \\
$\delta_{2}$ & induced death rate of suspected bandits \\
$\sigma_{3}$ & quitting rate of detainee \\
$\gamma_{3}$ & movement of detentes to prison \\
$\tau_{1}$ & rate of rehabilitate detnee \\
$\sigma_{4}$ & quitting rate of individuals in the prison \\
$\tau_{2}$ & rehabilitating rate of those in prison \\
$\sigma_{5}$ & treatment rate of those in rehabilitation center \\
\hline \hline
\end{tabular}

\subsection{Basic Qualitative Properties}

The basic properties of the model can now be investigated. 


\subsubsection{Positivity and boundedness of solutions}

Since model (1) monitors human population, all the parameters are non-negative. Therefore, it is important to proof that all the state variables are also non-negative for all time $t>0$.

Theorem 1. The state variables, $S(t), I(t), B(t), D(t), P(t), R(t)$ and $Q(t)$, of the model (1), with the initial data (2), remain non-negative for all $t>0$.

Proof. Noting that

$$
\lambda=\frac{\beta(I(t)+\eta B(t)}{N(t)},
$$

one sees from the first equation of (1) that

$$
\frac{d S}{d t} \geq-(\lambda+\mu) S(t)
$$

simplifying (4) gives,

$$
\frac{d}{d t}\left(S(t) \exp \left(\mu t+\int_{0}^{t} \lambda(\varpi) d \varpi\right)\right) \geq 0
$$

solving (5), gives

$$
S(t) \geq S(0) \exp \left(-\left(\mu t+\int_{0}^{t} \lambda(\varpi) d \varpi\right)\right)>0, \forall t>0 .
$$

The remaining state variables $I(t), B(t), D(t), P(t), R(t)$ and $Q(t)$, can be proved to be positive for all $t>0$ when the same approach been used for $S(t)$ is employed.

Next, consider the biologically feasible region, defined by $\Gamma \subset \mathbb{R}_{+}^{7}$ where

$$
\Gamma=\left\{(S, I, B, D, P, R, Q) \in \mathbb{R}_{+}^{7}: N \leq \frac{\pi}{\mu}\right\} .
$$

$\Gamma$ is shown positively invariant in a certain region.

The total population is given by

$$
\frac{d N}{d t} \leq \pi-\mu N
$$

which results into the solution $N(t)=N(0) \exp (-\mu t)+\frac{\pi}{N}(1-\exp (-\mu t))$. It follows that $N(t) \longrightarrow \frac{\pi}{\mu}$ as $\mathrm{t} \longrightarrow \infty$ in particular, $\mathrm{N}(\mathrm{t}) \leqslant \frac{\pi}{\mu}$ if $N(0) \leqslant \frac{\pi}{\mu}$ with respect to the illicit drug use and banditry model (1). Hence, it suffices to consider the dynamics of the model in $\Gamma$. In this region, the illicit drug use and banditry model can be considered as being mathematically and biologically well-posed [27]. 


\section{$3 \quad$ Stability and Sensitivity Analysis}

\subsection{Illicit drug use and banditry-free Equilibrium $\left(\mathcal{D}_{0}\right)$}

This is the equilibrium point where the illicit drug use and banditry is absent in the population, denoted by $\mathcal{D}_{0}$. At this point $I=B=0$ and so, setting the vector field of (1) to zero gives

$$
\mathcal{D}_{0}=\left(S_{0}, I_{0}, B_{0}, D_{0}, P_{0}, R_{0}\right)=\left(\frac{\pi}{\mu}, 0,0,0,0,0\right)
$$

The illicit drug use and banditry reproduction number $\mathcal{R}_{0}$ is established next.

\subsection{Illicit drug use and banditry threshold $\left(\mathcal{R}_{0}\right)$}

The IDUB reproduction number also noted as IDUB threshold, $\mathcal{R}_{0}$, given by (8), is the criterion of the IDUB spread in a complete naive population. Also, $\mathcal{R}_{0}$ can be defined as the average number of new cases of illicit drug user and bandit influenced by a typical illicit drug users and bandits in a naive population.

The next generation matrix method [28], the IDUB reproduction number, $\mathcal{R}_{0}$ is obtained as follows:

$$
F=\left(\begin{array}{ccccc}
\beta & \beta \eta & 0 & 0 & 0 \\
0 & 0 & 0 & 0 & 0 \\
0 & 0 & 0 & 0 & 0 \\
0 & 0 & 0 & 0 & 0 \\
0 & 0 & 0 & 0 & 0
\end{array}\right)
$$

and let $d_{1}=\sigma_{1}+\gamma_{1}+\delta_{1}+\mu, \quad d_{2}=\sigma_{2}+\gamma_{2}+\delta_{2}+\mu, \quad d_{3}=\sigma_{3}+\gamma_{3}+\tau_{1}+\mu$,

$$
d_{4}=\sigma_{4}+\tau_{2}+\delta_{4}+\mu, \quad d_{5}=\sigma_{5}+\alpha_{1}+\mu .
$$

$$
V=\left(\begin{array}{ccccc}
d_{1} & 0 & 0 & 0 & -\alpha_{1} \\
-\gamma_{1} & d_{2} & 0 & 0 & 0 \\
-\sigma_{1} & -\sigma_{2} & d_{3} & 0 & 0 \\
0 & -\gamma_{2} & -\gamma_{3} & d_{4} & 0 \\
0 & 0 & -\tau_{1} & -\tau_{2} & d_{5}
\end{array}\right)
$$

Therefore, the spectral radius of the matrix $\mathcal{F V}^{-1}$ is obtained, which is also $\mathcal{R}_{0}$, was determined in the sense of $[9,10, ?, ?]$ as

$$
\mathcal{R}_{0}=\frac{\beta d_{3} d_{4} d_{5}\left(d_{2}+\eta \gamma_{1}\right)}{d_{1} d_{2} d_{3} d_{4} d_{5}-\left(\left(d_{4} \tau_{1} \alpha_{1}+\tau_{2} \alpha_{1} \gamma_{3}\right)\left(d_{2} \sigma_{1}+\gamma_{1} \sigma_{2}\right)+d_{3} \tau_{2} \alpha_{1} \gamma_{1} \gamma_{2}\right)},
$$

Algebraic simplification shows that $d_{1} d_{2} d_{3} d_{4} d_{5}>\left(\left(d_{4} \tau_{1} \alpha_{1}+\tau_{2} \alpha_{1} \gamma_{3}\right)\left(d_{2} \sigma_{1}+\gamma_{1} \sigma_{2}\right)+d_{3} \tau_{2} \alpha_{1} \gamma_{1} \gamma_{2}\right)$.

To study the local asymptotic stability (LAS) of $\mathcal{D}_{0}$ given by (7), the illicit drug use and banditry reproduction number, $\mathcal{R}_{0}$, given by (8), is a major key needed for this analysis. The local asymptotically stability of $\mathcal{D}_{0}$ will be examined by the following theorem. 
Theorem 2. The illicit drug use and banditry-free equilibrium, $\mathcal{D}_{0}$, of the system (1) is locally asymptotically stable if $\mathcal{R}_{0}<1$ and unstable when $\mathcal{R}_{0}>1$.

Proof. Since the illicit drug use and banditry reproduction number, $\mathcal{R}_{0}$, was obtained using next generation matrix method by [28], it is suffice to proofed that the model (1) is locally asymptotically stable when $\mathcal{R}_{0}<1$

The significance of Theorem 2 shows that the problem of IDUB model governed by (1) will be wiped out from the population, if the initial size of the illicit drug user and bandits sub-populations are in the basin of attraction of the $\mathcal{D}_{0}$. However, illicit drug user and bandits obliteration is independent of the initial sizes if the $\mathcal{D}_{0}$ is globally asymptotically stable. The global stability result is established in the following theorem.

Theorem 3. The IDBFE of the model (1), given by (7), is globally asymptotically stable $(G A S)$ in the region $\Gamma$ whenever $\mathcal{R}_{0} \leq 1$.

Proof. Consider the linear Lyapunov function $\mathcal{L}: \Gamma \rightarrow \mathbb{R}$ defined by

$$
\begin{aligned}
\mathcal{L}= & S(t)+\frac{\alpha_{1}\left[\sigma_{2}\left(\gamma_{3} \tau_{2}+\tau_{1} d_{4}\right)+d_{3} \gamma_{2} \tau_{2}\right]}{d_{2} d_{3} d_{4} d_{5}} B(t)+\frac{\gamma_{3} \tau_{2} \alpha_{1}+\alpha_{1} \tau_{1} d_{4}}{d_{3} d_{4} d_{5}} D(t) \\
& +\frac{\tau_{2} \alpha_{1}}{d_{4} d_{5}} P(t)+\frac{\alpha_{1}}{d_{5}} R(t),
\end{aligned}
$$

The time derivative of (9) along the solution path of the system (1) is given by

$$
\begin{aligned}
\dot{\mathcal{L}}= & {\left[\lambda S+\alpha_{1} R-d_{1} I\right]+\frac{\alpha_{1}\left[\sigma_{2}\left(\gamma_{3} \tau_{2}+\tau_{1} d_{4}\right)+d_{3} \gamma_{2} \tau_{2}\right]}{d_{2} d_{3} d_{4} d_{5}}\left[\gamma_{1} I-d_{2} B\right] } \\
& +\frac{\gamma_{3} \tau_{2} \alpha_{1}+\alpha_{1} \tau_{1} d_{4}}{d_{3} d_{4} d_{5}}\left[\sigma_{1} I+\sigma_{2} B-d_{3} D\right]+\frac{\tau_{2} \alpha_{1}}{d_{4} d_{5}}\left[\gamma_{2} B+\gamma_{3} D-d_{4} P\right] \\
& +\frac{\alpha_{1}}{d_{5}}\left[\tau_{1} D+\tau_{2} P-d_{5} R\right], \\
= & {\left[\frac{\mu\left(d_{2}+\eta \gamma_{1}\right)}{\pi} \beta S(t)-d_{1}+\frac{\left(\alpha_{1} \sigma_{2}\left(\gamma_{3} \tau_{2}+\tau_{1} d_{4}\right)+\alpha_{1} d_{3} \gamma_{2} \tau_{2}\right) \gamma_{1}}{d_{2} d_{3} d_{4} d_{5}}+\frac{\left(\gamma_{3} \alpha_{1} \tau_{2}+\alpha_{1} \tau_{1} d_{4}\right)}{d_{3} d_{4} d_{5}}\right] I(t), } \\
\leq & {\left[\frac{\beta\left(d_{2}+\eta \gamma_{1}\right)}{d_{2}}-\frac{d_{1} d_{2} d_{3} d_{4} d_{5}-\left(\left(\alpha_{1} \sigma_{2} \gamma_{1}+d_{2} \sigma_{1} \alpha_{1}\right)\left(\gamma_{3} \tau_{2}+\tau_{1} d_{4}\right)+\alpha_{1} \gamma_{1} \gamma_{2} \tau_{2} d_{3}\right)}{d_{2} d_{3} d_{4} d_{5}}\right] I(t), \text { since } S(t) \leq \frac{\pi}{\mu} \text { in } \Gamma, } \\
= & \frac{d_{2} d_{3} d_{4} d_{5}}{d_{1} d_{2} d_{3} d_{4} d_{5}-\left(\left(\alpha_{1} \sigma_{2} \gamma_{1}+d_{2} \sigma_{1} \alpha_{1}\right)\left(\gamma_{3} \tau_{2}+\tau_{1} d_{4}\right)+\alpha_{1} \gamma_{1} \gamma_{2} \tau_{2} d_{3}\right)}\left[1-\mathcal{R}_{0}\right] I(t) .
\end{aligned}
$$

Thus, $\dot{\mathcal{L}} \leq 0$ if $\mathcal{R}_{0} \leq 1$ with $\dot{\mathcal{L}}=0$ if and only if $I(t)=0$. This shows that as $t \longrightarrow \infty$, then $(S(t), I(t), B(t), D(t), P(t), R(t)) \longrightarrow\left(\frac{\pi}{\mu}, 0,0,0,0,0\right)$. It follows that the largest compact invariant set in $\{(S(t), I(t), B(t), D(t), P(t), R(t)) \in \Gamma: \dot{\mathcal{L}}=0\}$ is the singleton $\left\{\mathcal{D}_{0}\right\}$. Therefore, by LaSalle's Invariance Principle [29], the illicit drug use and banditry-free equilibrium given by $\mathcal{D}_{0}$ is GAS in $\Gamma$ if $\mathcal{R}_{0} \leq 1$.

The deduction of Theorem 4 proofed that diminution or evacuation of IDUB is not dependent on the initial sizes of the illicit drug users and bandits in the population. The stability property is shown in Figure 2, where all the solutions meet to illicit drug use and banditry-free equilibrium. Hence, illicit drug use and banditry can be evacuated, if the associated illicit drug use and banditry reproduction number is less than one. 


\subsection{Illicit drug use and banditry-present equilibrium}

The steady-state solution of model (1) when all the state variables are positive is referred to as the illicit drug use and banditry-present equilibrium point (IDBPE) denoted and given by

$$
\mathcal{D}^{*}=\left(S^{*}, I^{*}, B^{*}, D^{*}, P^{*}, R^{*}\right) .
$$

Then, setting the right hand sides of (1) to zero, the following are obtained in terms of $\lambda$ :

$$
\begin{gathered}
S_{\lambda}^{*}=\frac{\pi}{\lambda+\mu}, \\
I_{\lambda}^{*}=\frac{\pi \lambda \alpha_{1} A_{1}}{d_{1}\left[k_{4}-A_{8} \alpha_{1}(\lambda+\mu)\right]} \\
B_{\lambda}^{*}=\frac{\pi \lambda\left(A_{7}-\left(A_{5}+A_{6}\right) \alpha_{1}(\lambda+\mu)\right)}{k_{9}\left[k_{4}-A_{8} \alpha_{1}(\lambda+\mu)\right]}, \\
D_{\lambda}^{*}=\frac{\pi \lambda k_{2}\left(k_{4}-\alpha_{1}\left(A_{2}-A_{3}(\lambda+\mu)\right)\right.}{k_{7}\left[k_{4}-A_{8} \alpha_{1}(\lambda+\mu)\right]}, \\
P_{\lambda}^{*}=\frac{\pi \lambda A_{4}\left(k_{4}+\alpha_{1} A_{5}(\lambda+\mu)\right)}{k_{8}\left[k_{4}-A_{8} \alpha_{1}(\lambda+\mu)\right]} \\
R_{\lambda}^{*}=\frac{\pi \lambda A_{2}}{k_{4}-A_{8} \alpha_{1}(\lambda+\mu)},
\end{gathered}
$$

where

$$
\begin{aligned}
& k_{1}=d_{1} \tau_{1}+\tau_{2} \gamma_{2}, \quad k_{2}=\sigma_{1} d_{2}+\sigma_{2} \gamma_{1}, \quad k_{3}=\tau_{2} \gamma_{1} \gamma_{2} d_{3}, \quad k_{4}=d_{1} d_{2} d_{3} d_{4} d_{5}, \\
& k_{5}=\tau_{1} d_{4}+\gamma_{1} \gamma_{2} d_{3}+\gamma_{3} \tau_{2}, \quad k_{6}=\gamma_{1} \gamma_{2} d_{3}, \quad k_{7}=d_{1} d_{2} d_{3}, \quad k_{8}=d_{1} d_{2} d_{3} d_{4} \text {, } \\
& k_{9}=d_{1} d_{2} \quad A_{1}=k_{4}-k_{2} k_{6}+k_{3}, \quad A_{2}=k_{1} k_{2}+k_{3}, \quad A_{3}=k_{1} k_{2}+k_{6} \text {, } \\
& A_{4}=k_{6}+\gamma_{3} k_{2}, \quad A_{5}=k_{6}\left(\tau_{2}-k_{2}\right), \quad A_{6}=k_{1} k_{2}\left(\gamma_{1}-1\right), \\
& A_{7}=\gamma_{1} k_{4}, \quad A_{8}=k_{2} k_{5} \alpha_{1} \text {. } \\
& \lambda^{*}=\frac{\beta\left(I^{*}+\eta B^{*}\right)}{N^{*}}
\end{aligned}
$$

and

$$
N^{*}=S^{*}+I^{*}+B^{*}+D^{*}+P^{*}+R^{*} .
$$

Substituting (11) and (13) into equation (12) after algebraic manipulations, gives the following

$$
\lambda=0 \quad \text { or } \quad \lambda=\mu\left(\mathcal{R}_{0}-1\right) .
$$

When $\lambda=0$ from system (11), it means illicit drug use and banditry-present equilibrium does not exist, but we have illicit drug use and banditry-free equilibrium, and when $\lambda=$ $\mu\left(\mathcal{R}_{0}-1\right)$, we have a unique illicit drug use and banditry-present equilibrium if $\mathcal{R}_{0}>1$. Simplifying (11), the following unique illicit drug use and banditry-present equilibrium $\mathcal{D}^{*}$ is obtained in terms of $\mathcal{R}_{0}$ as follows

$$
S^{*}=\frac{\pi}{\mu \mathcal{R}_{0}}
$$




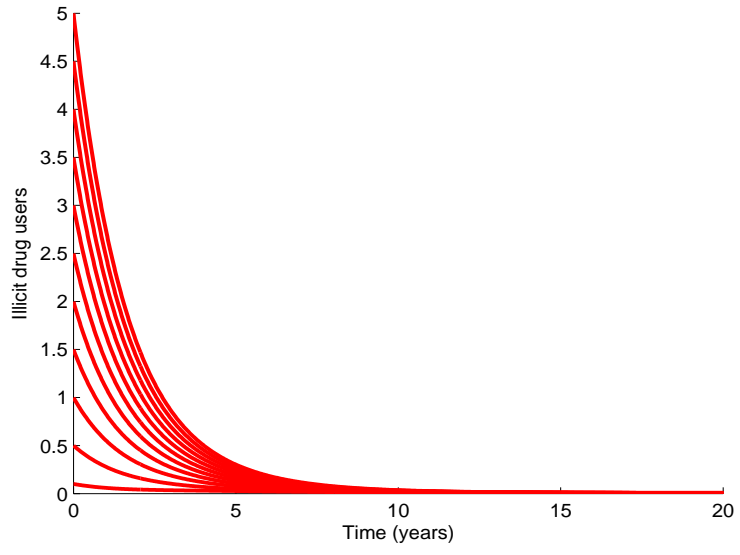

(a)

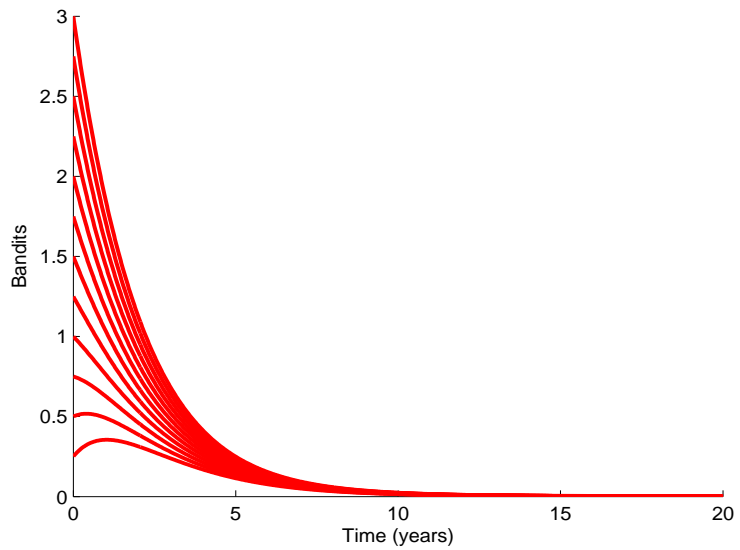

(b)

Figure 2: Simulated results of model (1) illustrating the global dynamics of illicit drug use and banditry-free with different initial sizes. Parameter values used are given in Table 3 except: $\beta=0.04$ and $\sigma_{5}=0.7$, so that, $\mathcal{R}_{0}<1$.

$$
\begin{gathered}
I^{*}=\frac{\pi \mu\left(\mathcal{R}_{0}-1\right) \alpha_{1} A_{1}}{d_{1}\left[k_{4}-A_{8} \alpha_{1} \mu \mathcal{R}_{0}\right]}, \\
B^{*}=\frac{\mu \pi\left(\mathcal{R}_{0}-1\right)\left(A_{7}-\left(A_{5}+A_{6}\right) \alpha_{1} \mu \mathcal{R}_{0}\right)}{k_{9}\left[k_{4}-A_{8} \alpha_{1} \mu \mathcal{R}_{0}\right]} \\
D^{*}=\frac{\mu \pi\left(\mathcal{R}_{0}-1\right) k_{2}\left(k_{4}-\alpha_{1}\left(A_{2}-A_{3} \mu \mathcal{R}_{0}\right)\right.}{\left.k_{7}\left[k_{4}-A_{8} \alpha_{1} \mu \mathcal{R}_{0}\right)\right]}, \\
P^{*}=\frac{\pi \mu\left(\mathcal{R}_{0}-1\right) A_{4}\left(k_{4}+\alpha_{1} A_{5} \mu \mathcal{R}_{0}\right)}{k_{8}\left[k_{4}-A_{8} \alpha_{1} \mu \mathcal{R}_{0}\right]}, \\
R^{*}=\frac{\pi \mu A_{2}\left(\mathcal{R}_{0}-1\right)}{k_{4}-A_{8} \alpha_{1} \mu \mathcal{R}_{0}} .
\end{gathered}
$$

Also, when $\mathcal{R}_{0}=1$ from system (15), it means we have illicit drug use and banditry-free equilibrium but illicit drug use and banditry-present equilibrium does not exist. Similarly, we have a unique illicit drug use and banditry-present equilibrium when $\mathcal{R}_{0}>1$.

To further examine the nature of its stability when $\mathcal{R}_{0}=1$, the bifurcation analysis will be explored next.

\subsection{Forward Bifurcation}

To study the existence of bifurcation of the model (1), center manifold theory being described in Castillo-Chavez and Song [30] will be explored. The illicit drug use and banditry model (1) will be written in the vector form for this purpose:

$$
\frac{d X}{d t}=F(X)
$$




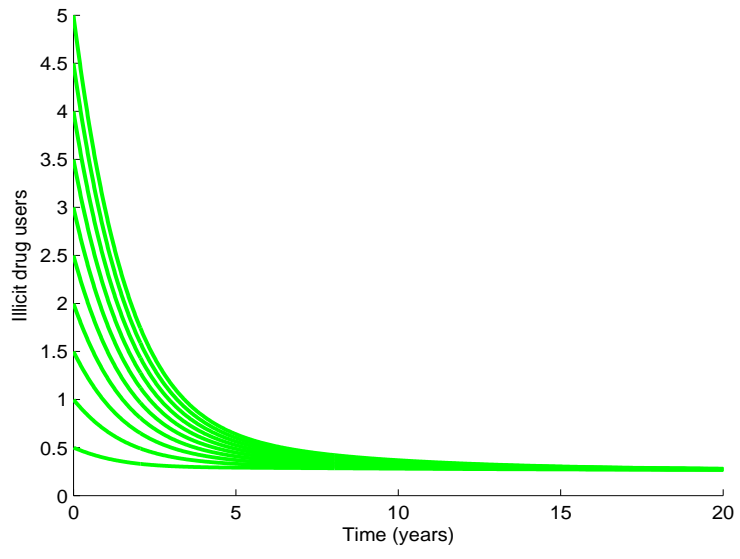

(a)

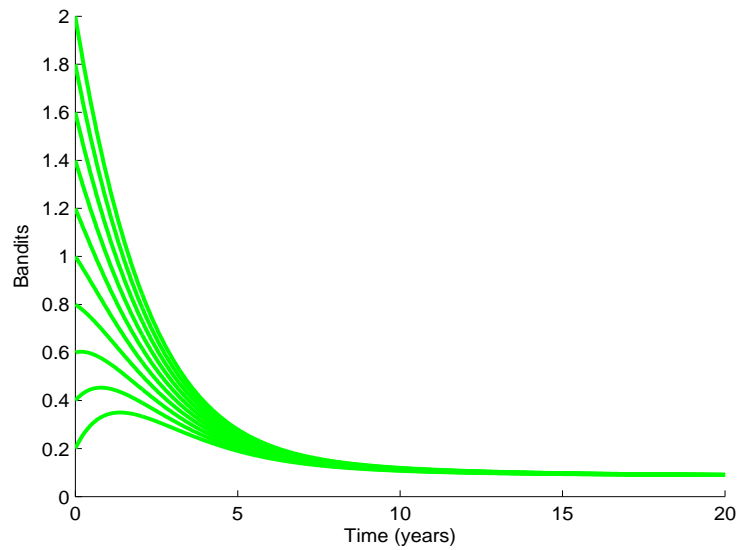

(b)

Figure 3: Simulated results of model (1) illustrating the convergence of solution trajectories with different initial sizes to the illicit drug use and banditry-present equilibrium. Parameter values used are given in Table 3, such that $\mathcal{R}_{0}>1$.

where $\mathrm{X}=\left(x_{1}, x_{2}, x_{3}, x_{4}, x_{5}, x_{6}\right)^{T}$ and $\mathrm{F}=\left(f_{1}, f_{2}, f_{3}, f_{4}, f_{5}, f_{6}\right)^{T}$ with $S(t)=x_{1}, I(t)=$ $x_{2}, B(t)=x_{3}, D(t)=x_{4}, P(t)=x_{5}, R(t)=x_{6}$. Then, model (1) becomes

$$
\begin{aligned}
& f_{1}=\frac{d x_{1}}{d t}=\pi-\lambda x_{1}-\mu x_{1}, \\
& f_{2}=\frac{d x_{2}}{d t}=\lambda x_{1}+\alpha_{1} x_{6}-\left(\sigma_{1}+\gamma_{1}+\delta_{1}+\mu\right) x_{2}, \\
& f_{3}=\frac{d x_{3}}{d t}=\gamma_{1} x_{2}-\left(\sigma_{2}+\gamma_{2}+\delta_{2}+\mu\right) x_{3}, \\
& f_{4}=\frac{d x_{4}}{d t}=\sigma_{1} x_{2}+\sigma_{2} x_{3}-\left(\sigma_{3}+\gamma_{3}+\tau_{1}+\mu\right) x_{4}, \\
& f_{5}=\frac{d x_{5}}{d t}=\gamma_{2} x_{3}+\gamma_{3} x_{4}-\left(\sigma_{4}+\tau_{2}+\delta_{4}+\mu\right) x_{5}, \\
& f_{6}=\frac{d x_{6}}{d t}=\tau_{1} x_{4}+\tau_{2} x_{5}-\left(\sigma_{5}+\alpha_{1}+\mu\right) x_{6} .
\end{aligned}
$$

At $\mathcal{R}_{0}=1$ in (8), the bifurcation parameter $\beta^{*}$ can be obtained as

$$
\beta^{*}=\frac{d_{1} d_{2} d_{3} d_{4} d_{5}-\left(\left(d_{4} \tau_{1} \alpha_{1}+\tau_{2} \alpha_{1} \gamma_{3}\right)\left(d_{2} \sigma_{1}+\gamma_{1} \sigma_{2}\right)+d_{3} \tau_{2} \alpha_{1} \gamma_{1} \gamma_{2}\right)}{d_{3} d_{4} d_{5}\left(d_{2}+\eta \gamma_{1}\right)}
$$


The linearized matrix of the system (16) around $\mathcal{D}_{0}$ and evaluated at $\beta^{*}$ is given by

$$
\mathcal{J}_{\left(\mathcal{D}_{0}, \beta^{*}\right)}=\left(\begin{array}{cccccc}
-\mu & -\beta^{*} & -\beta^{*} \eta & 0 & 0 & 0 \\
0 & \beta^{*}-d_{1} & \beta^{*} \eta & 0 & 0 & \alpha_{1} \\
0 & \gamma_{1} & -d_{2} & 0 & 0 & 0 \\
0 & \sigma_{1} & \sigma_{2} & -d_{3} & 0 & 0 \\
0 & 0 & \gamma_{2} & \gamma_{3} & -d_{4} & 0 \\
0 & 0 & 0 & \tau_{1} & \tau_{2} & -d_{5}
\end{array}\right)
$$

The eigenvalues $\lambda$ of $\mathcal{J}_{\left(\mathcal{D}_{0}, \beta^{*}\right)}$ given by the matrix above are the roots of the characteristic equation of the form

$$
(\lambda+\mu) P(\lambda)=0,
$$

where $P(\lambda)$ is a polynomial of degree four whose roots are all negative except one zero eigenvalue. The left eigenvector, $v=\left(v_{1}, v_{2}, \ldots, v_{6}\right)$, corresponding to the simple zero eigenvalue of (16) is obtained from $v \mathcal{J}_{\left(\mathcal{D}_{0}, \beta^{*}\right)}=0$ as

$$
\begin{gathered}
v_{1}=0, \quad v_{2}=\frac{d_{5}}{\alpha_{1}} v_{6}, \quad v_{3}=\frac{\beta^{*} \eta d_{3} d_{4} d_{5}+\sigma_{2} \alpha_{1}\left(\tau_{2} \gamma_{3}+\tau_{1} d_{4}\right)+\gamma_{2} \tau_{2} \alpha 1 d 3}{\alpha 1 d_{2} d_{3} d_{4}} v_{6}, \\
v_{4}=\frac{\tau_{2} \gamma_{3}+\tau_{1} d_{4}}{d_{3} d_{4}} v_{6}, \quad v_{5}=\frac{\tau_{2}}{d_{4}} v_{6} .
\end{gathered}
$$

Further, the right eigenvector, $w=\left(w_{1}, w_{2}, \ldots, w_{6}\right)^{T}$, associated with this simple zero eigenvalue can be obtained from $w \mathcal{J}_{\left(\mathcal{D}_{0}, \beta^{*}\right)}=0$. As a result, we have

$$
\begin{aligned}
& w_{1}=\frac{-\beta^{*}\left(d_{2}+\eta \gamma_{1}\right)}{\mu d_{2}} w_{2}, \quad w_{3}=\frac{\gamma_{1}}{d_{2}} w_{2}, \quad w_{5}=\frac{\gamma_{1} \gamma_{2} d_{3}+\gamma_{3}\left(\sigma_{1} d_{2}+\sigma_{2} \gamma_{1}\right)}{d_{2} d_{3} d_{4}} w_{2}, \\
& w_{4}=\frac{\sigma_{1} d_{2}+\sigma_{2} \gamma_{1}}{d_{2} d_{3}} w_{2}, \quad w_{6}=\frac{\tau_{1} d_{4}\left(\sigma_{1} d_{2}+\sigma_{2} \gamma_{1}\right)+\tau_{2}\left(\gamma_{1} \gamma_{2} d_{3}+\gamma_{3}\left(\sigma_{1} d_{2}+\sigma_{2} \gamma_{1}\right)\right)}{d_{2} d_{3} d_{4} d_{5}} w_{2} .
\end{aligned}
$$

It should be noted that the components of $w$ and $v$ are obtained so that $v \cdot w=1$ as required in [30]. All the second-order partial derivatives of $f_{i}, i=i=1,2 \ldots, 6$, from the system (16) are zero at point $\left(\mathcal{D}_{0}, \beta^{*}\right)$ except the following :

$$
\begin{aligned}
& \frac{\partial^{2} f_{1}}{\partial x_{1} \partial x_{2}}=\frac{\partial^{2} f_{1}}{\partial x_{2} \partial x_{1}}=\frac{-\beta^{*} \mu}{\pi}, \quad \frac{\partial^{2} f_{1}}{\partial x_{1} \partial x_{3}}=\frac{\partial^{2} f_{1}}{\partial x_{3} \partial x_{1}}=\frac{-\beta^{*} \mu \eta}{\pi}, \\
& \frac{\partial^{2} f_{2}}{\partial x_{1} \partial x_{2}}=\frac{\partial^{2} f_{2}}{\partial x_{2} \partial x_{1}}=\frac{\beta^{*} \mu}{\pi}, \quad \frac{\partial^{2} f_{2}}{\partial x_{1} \partial x_{3}}=\frac{\partial^{2} f_{2}}{\partial x_{3} \partial x_{1}}=\frac{\beta^{*} \mu \eta}{\pi},
\end{aligned}
$$

with

$$
\frac{\partial^{2} f_{1}}{\partial x_{2} \partial \beta}=-1, \quad \frac{\partial^{2} f_{1}}{\partial x_{3} \partial \beta}=-\eta, \quad \frac{\partial^{2} f_{2}}{\partial x_{2} \partial \beta}=1, \quad \frac{\partial^{2} f_{2}}{\partial x_{3} \partial \beta}=\eta .
$$

The direction of the bifurcation at $\mathcal{R}_{0}=1$ is determined by the signs of the bifurcation coefficients $\mathbf{a}$ and $\mathbf{b}$, define as follow:-

$$
a=\sum_{k, i, j=1}^{6} v_{k} w_{i} w_{j} \frac{\partial^{2} f_{k}}{\partial x_{i} \partial x_{j}}\left(\mathcal{D}_{0}, \beta^{*}\right)
$$


and

$$
b=\sum_{k, i=1}^{6} v_{k} w_{i} \frac{\partial^{2} f_{k}}{\partial x_{i} \partial \beta}\left(\mathcal{D}_{0}, \beta^{*}\right) .
$$

Since $v_{1}=0$, then $(23)$ and $(24)$ can be written as

$$
a=v_{2} w_{1} w_{2} \frac{\partial^{2} f_{2}}{\partial x_{1} \partial x_{2}}+v_{2} w_{1} w_{3} \frac{\partial^{2} f_{2}}{\partial x_{1} \partial x_{3}}
$$

and

$$
b=v_{2} w_{2} \frac{\partial^{2} f_{2}}{\partial x_{2} \partial \beta}+v_{2} w_{3} \frac{\partial^{2} f_{2}}{\partial x_{3} \partial \beta} .
$$

Substituting (17), (19), (20), (21) and (22) into (25) and (26) gives the following

$$
a=\frac{-d_{5} \mu^{2}}{\pi \alpha_{1}} w_{2}^{2} v_{6}
$$

and

$$
b=\frac{d_{5}\left(d_{2}+\gamma_{1} \eta\right)}{\alpha_{1} d_{2}} .
$$

As we can see $a<0$ and $b>0$, it follows that the IDUB model (1) exhibits a forward bifurcation and $\mathcal{D}^{*}$ is locally stable. This result is claimed as follows.

Theorem 4. The IDUB model governed by (1) exhibits a forward bifurcation at the threshold $\mathcal{R}_{0}=1$ (or, equivalently, there exists an illicit drug use and banditry-present equilibrium, $\mathcal{D}^{*}$, which is locally asymptotically stable whenever $\mathcal{R}_{0}>1$, but near $\mathcal{R}_{0}=1$ ).

The significance of the above result is that a small inflow of illicit drug user and bandit into a completely susceptible population will cause a raise the spread of illicit drug use and banditry the population within the community whenever $\mathcal{R}_{0}>1$. Nevertheless, the initial sizes of the illicit drug users and bandits in the population is a critical factor of this result. Hence, to show that the elimination and persistence of illicit drug use and banditry does not depend on the initial sizes of the illicit drug users and bandits, we established the global stability of IDBPE in the next Section.

\subsection{Global stability of IDBPE}

Theorem 5. The unique IDBPE of the illlicit drug use and banditry model (1), given by (15), is globally asymptotically stable $(G A S)$ in $\Gamma \backslash \Gamma_{0}$ when $\mathcal{R}_{0}>1, D R^{* *} \leq D^{* *} R, D P^{* *} \leq$ $D^{* *} P$ and $P R^{* *} \leq P^{* *} R$. 


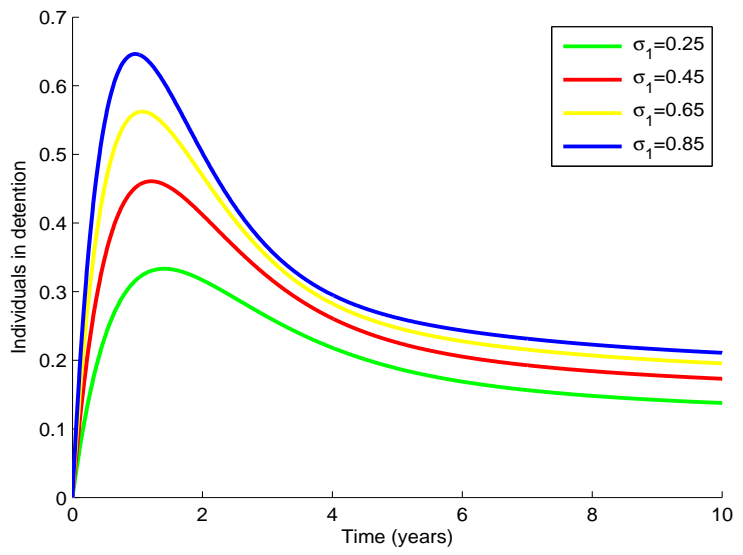

(a)

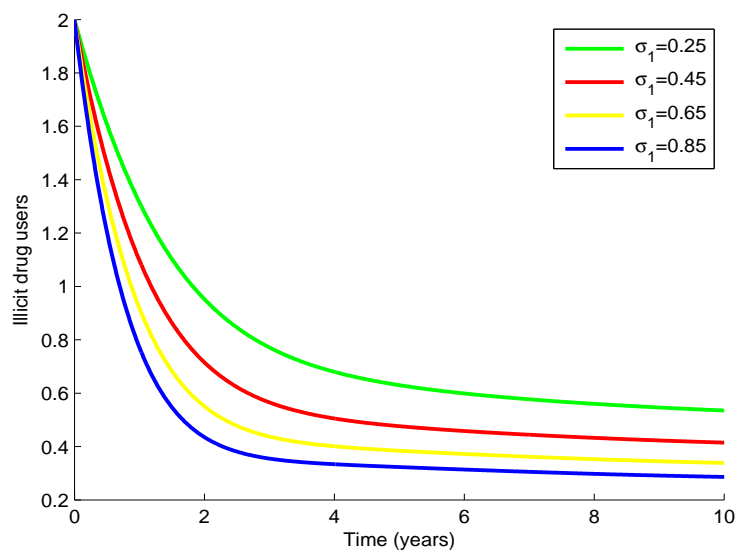

(c)

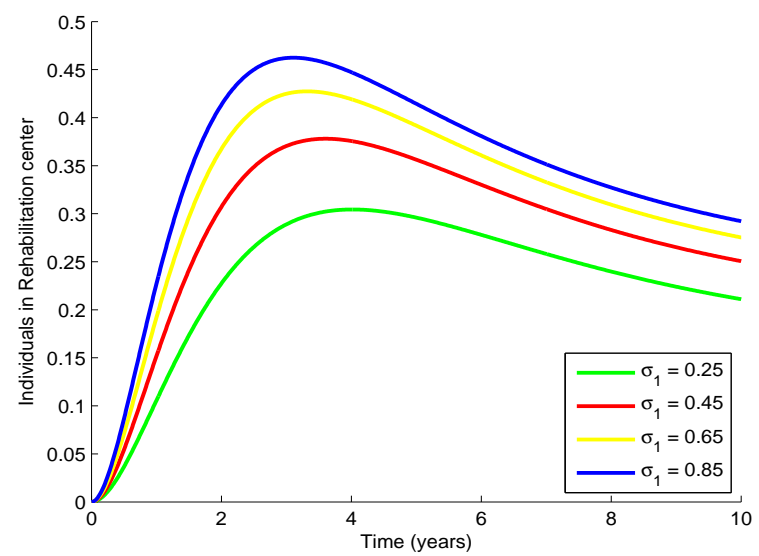

(e)

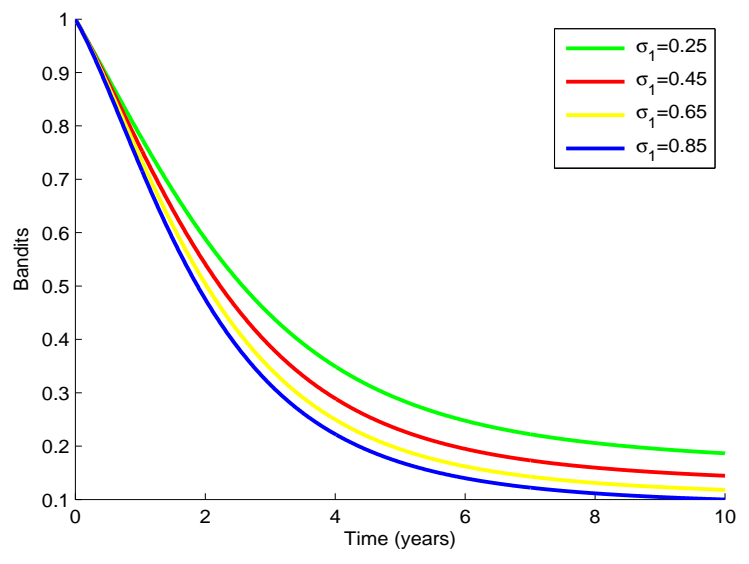

(b)

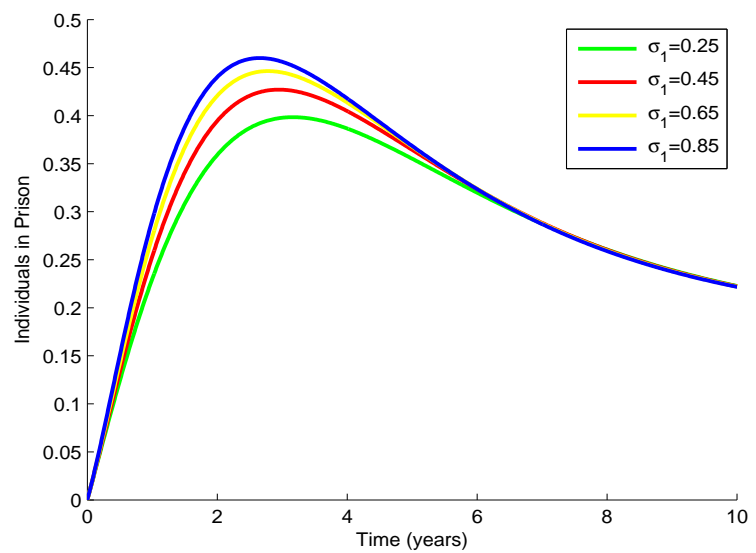

(d)

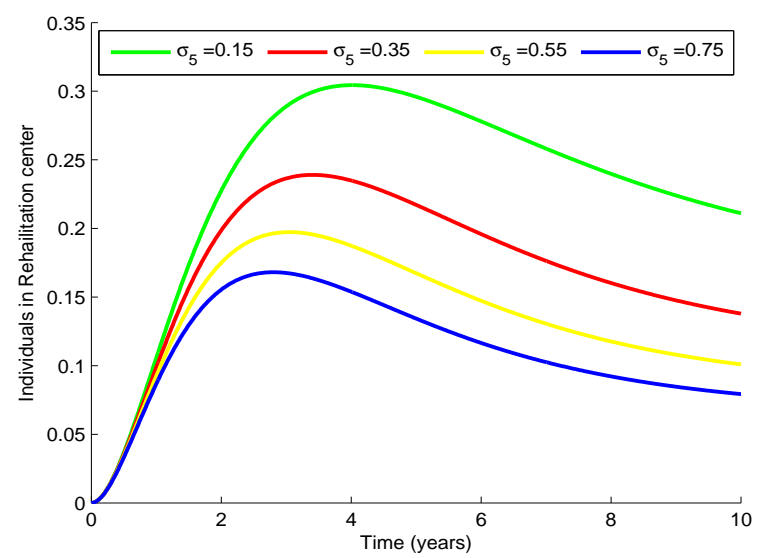

(f)

Figure 4: Simulation results of model (1) with the effect of $\sigma_{1}$ and $\sigma_{5}$ on (a) Individuals in detention; (b) Bandits; (c) Illicit drug users (d) Individuals in prison and (e)-(f) Individuals in rehabilitation center. 


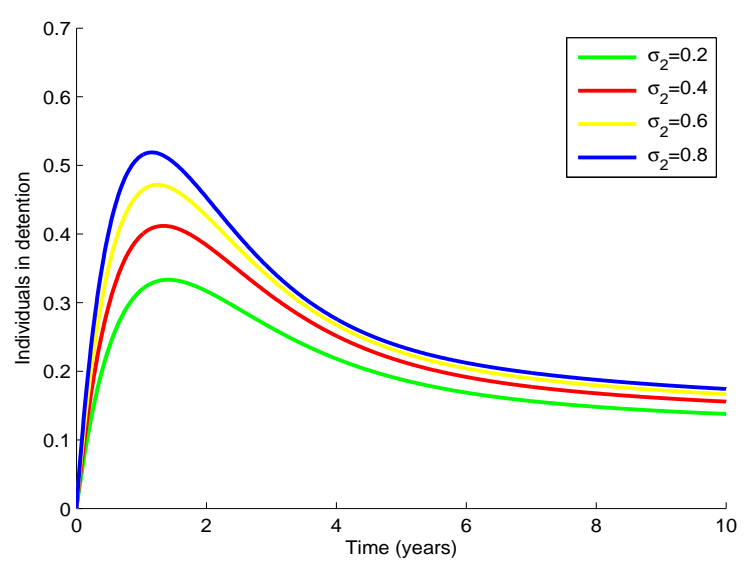

(a)

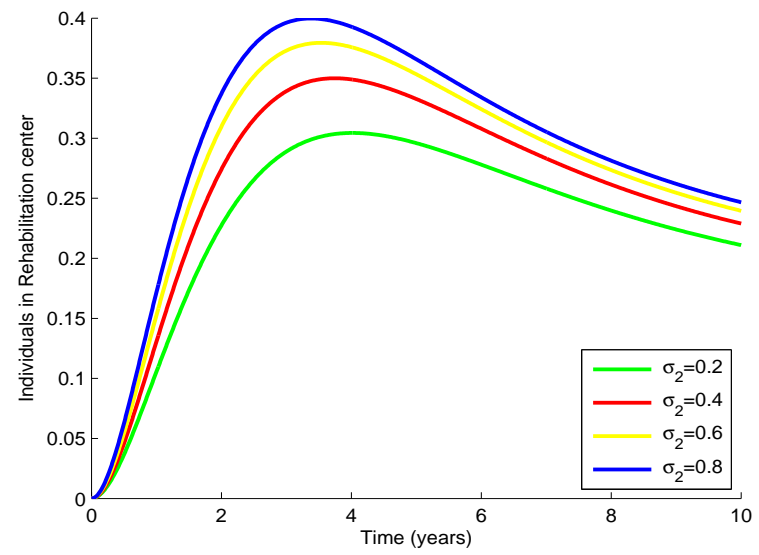

(c)

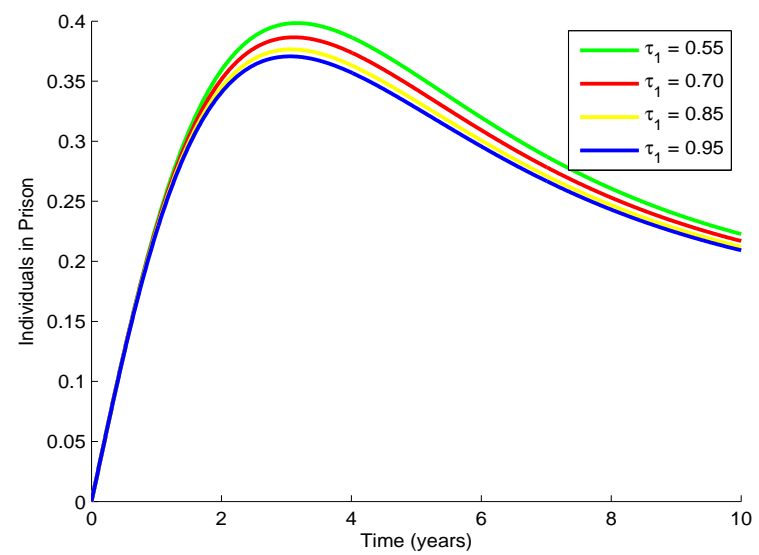

(e)

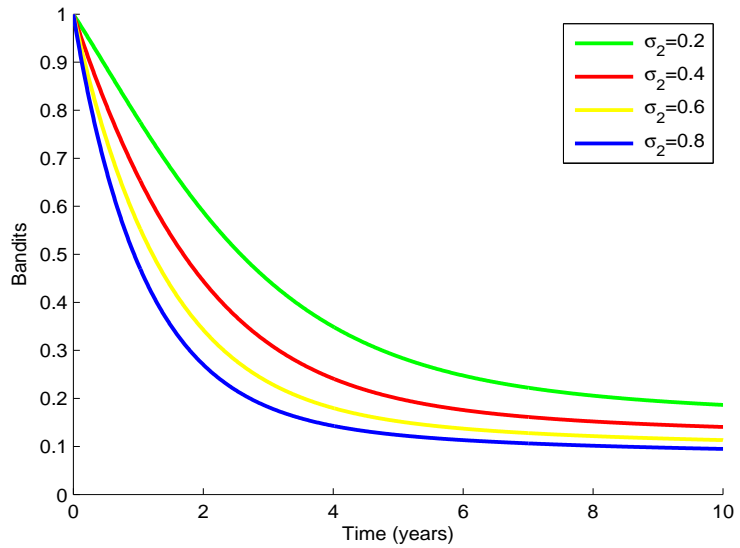

(b)

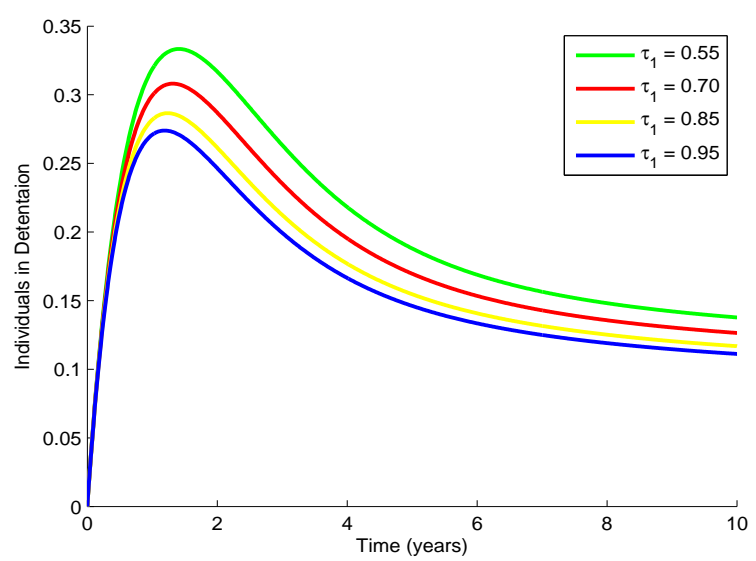

(d)

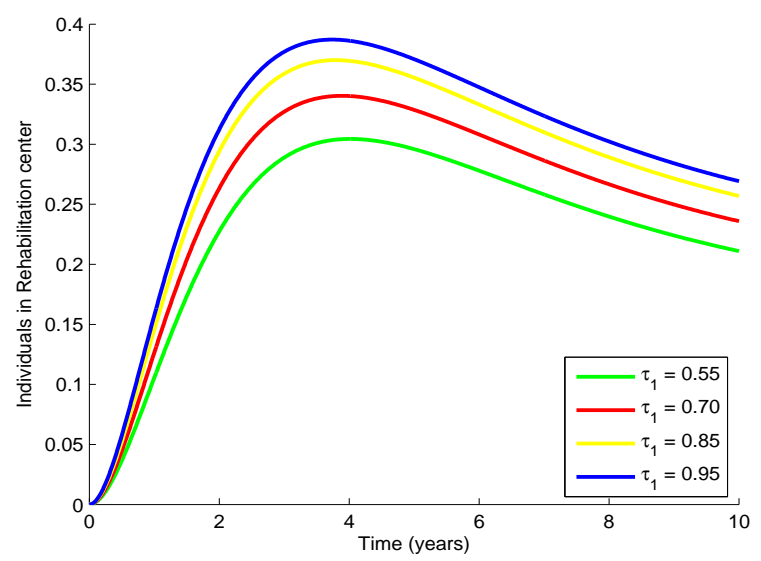

(f)

Figure 5: Simulation results of model (1) with the effect of $\sigma_{2}$ and $\tau_{1}$ on (a) Individuals in detention; (b) Bandits; (c) Individuals in rehabilitation center (d) Individuals in detention; (e) Individuals in prison and (f) Individuals in rehabilitation center. 


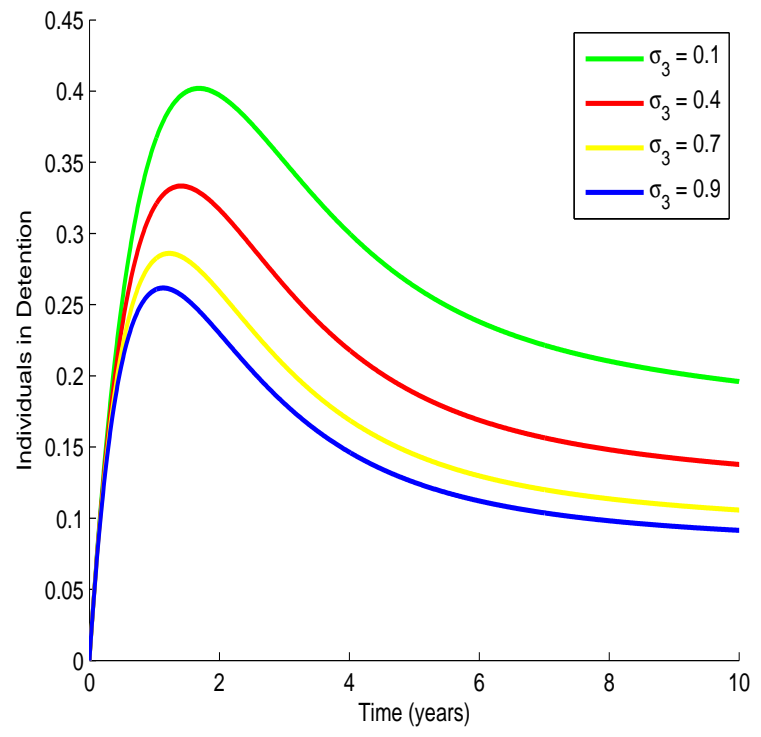

(a)

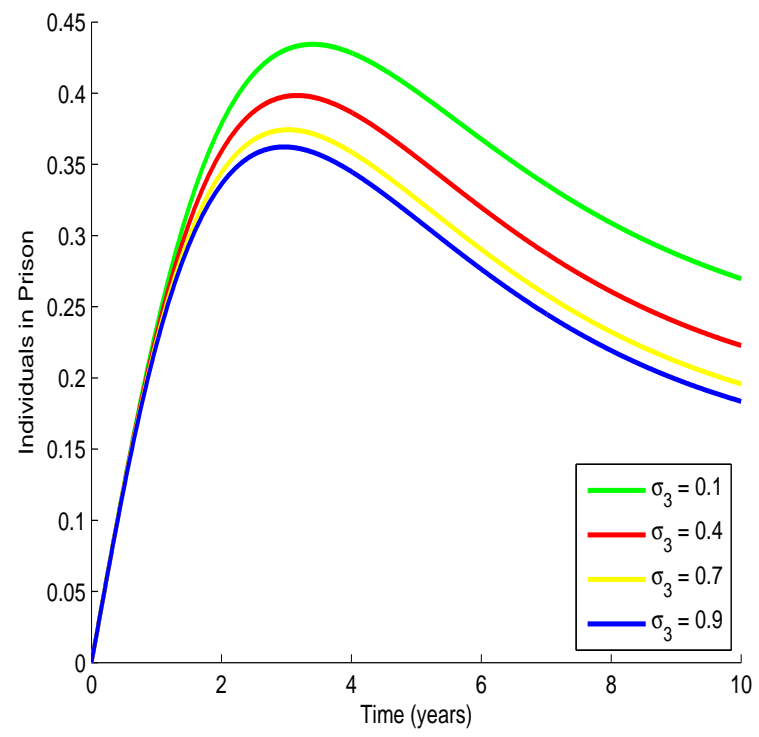

(c)

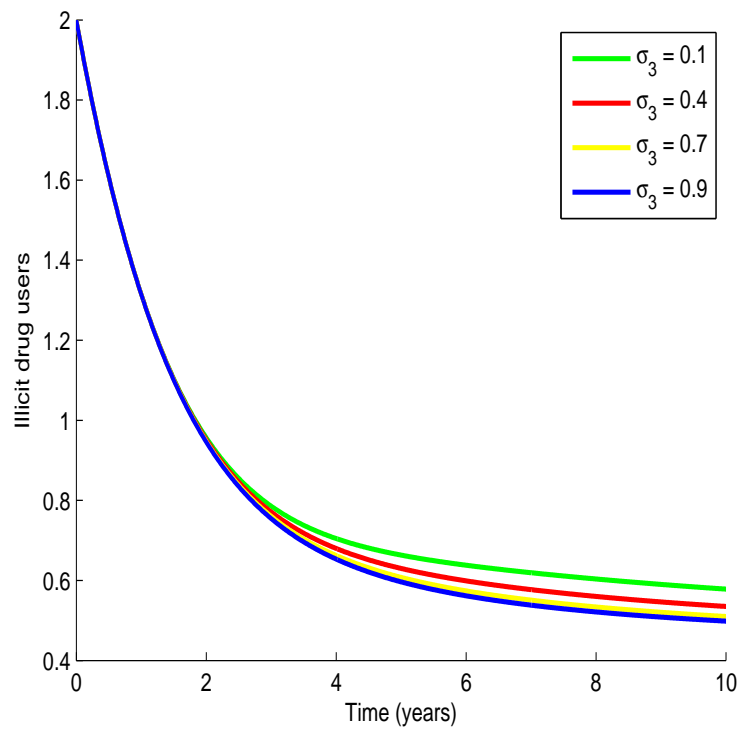

(b)

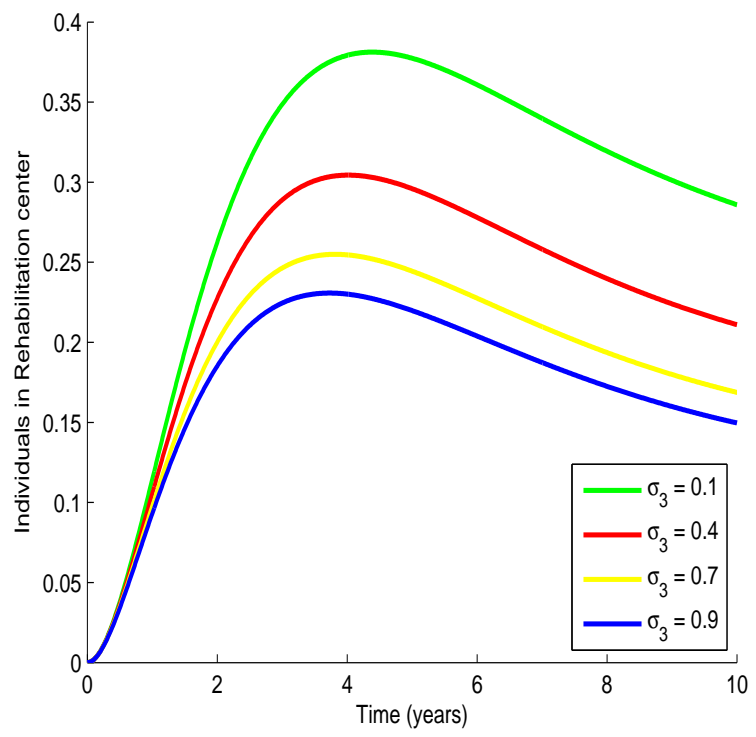

(d)

Figure 6: Simulation results of model (1) with the effect of $\sigma_{3}$ on (a) Individuals in detention; (b) Illicit drug users; (c) Individuals in prison and (d) Individuals in rehabilitation center. 
Proof. Consider the non-linear Lyapunov function $\mathfrak{F}: \Gamma \backslash \Gamma_{0} \rightarrow \mathbb{R}$ defined by

$$
\begin{aligned}
\mathfrak{F}= & S-S^{* *}-S^{* *} \ln \frac{S}{S^{* *}}+\left(I-I^{* *}-I^{* *} \ln \frac{I}{I^{* *}}\right)+\frac{\alpha_{1} \tau_{1}\left(\gamma_{3}+d_{4}\right)}{d_{3} d_{4} d_{5}}\left(D-D^{* *}-D^{* *} \ln \frac{D}{D^{* *}}\right) \\
& +\frac{d_{3} d_{4} d_{5}\left(d_{1}+\beta S^{* *}\right)+\sigma_{1} \alpha_{1} \tau_{1}\left(\gamma_{3}+d_{4}\right)}{d_{3} d_{4} d_{5} \gamma_{1}}\left(B-B^{* *}-B^{*} \ln \frac{B}{B^{* *}}\right) \\
& +\frac{\alpha_{1} \tau_{1}}{d_{4} d_{5}}\left(P-P^{* *}-P^{* *} \ln \frac{P}{P^{* *}}\right)+\frac{\alpha_{1}}{d_{5}}\left(R-R^{* *}-R^{* *} \ln \frac{R}{R^{* *}}\right),
\end{aligned}
$$

which is of Goh-Volterra type (see, e.g., [31, 32, 33]). The Lyapunov derivative is given by

$$
\begin{aligned}
\frac{d \mathfrak{F}}{d t}= & \frac{d S}{d t}-\frac{S^{* *}}{S} \frac{d S}{d t}+\left(\frac{d I}{d t}-\frac{I^{* *}}{I} \frac{d I}{d t}\right)+\frac{d_{3} d_{4} d_{5}\left(d_{1}+\beta S^{* *}\right)+\sigma_{1} \alpha_{1} \tau_{1}\left(\gamma_{3}+d_{4}\right)}{d_{3} d_{4} d_{5} \gamma_{1}}\left(\frac{d B}{d t}-\frac{B^{* *}}{B} \frac{d B}{d t}\right) \\
& +\frac{\alpha_{1} \tau_{1}\left(\gamma_{3}+d_{4}\right)}{d_{3} d_{4} d_{5}}\left(\frac{d D}{d t}-\frac{D^{* *}}{D} \frac{d D}{d t}\right)+\frac{\alpha_{1} \tau_{1}}{d_{4} d_{5}}\left(\frac{d P}{d t}-\frac{P^{* *}}{P} \frac{d P}{d t}\right)+\frac{\alpha_{1}}{d_{5}}\left(\frac{d R}{d t}-\frac{R^{* *}}{R} \frac{d R}{d t}\right) .
\end{aligned}
$$

Let $\frac{\beta(I(t)+\eta B(t))}{N(t)}=\tilde{\beta}(I(t)+\eta B(t))$, then putting the appropriate equations of the system (1) into (30), one obtains

$$
\begin{aligned}
\frac{d \mathfrak{F}}{d t}= & \left(1-\frac{S^{* *}}{S}\right)(\pi-\tilde{\beta}(I(t)+\eta B(t)) S(t)-\mu S(t)) \\
& +\left(1-\frac{I^{* *}}{I}\right)\left(\tilde{\beta}(I(t)+\eta B(t)) S(t)+\alpha_{1} R(t)-\left(\sigma_{1}+\gamma_{1}+\delta_{1}+\mu\right) I(t)\right) \\
& +\frac{d_{3} d_{4} d_{5}\left(d_{1}+\beta S^{* *}\right)+\sigma_{1} \alpha_{1} \tau_{1}\left(\gamma_{3}+d_{4}\right)}{d_{3} d_{4} d_{5} \gamma_{1}}\left(1-\frac{B^{* *}}{B}\right)\left(\gamma_{1} I(t)-\left(\sigma_{2}+\gamma_{2}+\delta_{2}+\mu\right) B(t)\right) \\
& +\frac{\alpha_{1} \tau_{1}\left(\gamma_{3}+d_{4}\right)}{d_{3} d_{4} d_{5}}\left(1-\frac{D^{* *}}{D}\right)\left(\sigma_{1} I(t)+\sigma_{2} B(t)-\left(\sigma_{3}+\gamma_{3}+\tau_{1}+\mu\right) D(t)\right) \\
& +\frac{\alpha_{1} \tau_{1}}{d_{4} d_{5}}\left(1-\frac{P^{* *}}{P}\right)\left(\gamma_{2} B(t)+\gamma_{3} D(t)-\left(\sigma_{4}+\tau_{2}+\delta_{4}+\mu\right) P(t)\right) \\
& +\frac{\alpha_{1}}{d_{5}}\left(1-\frac{R^{* *}}{R}\left(\tau_{1} D(t)+\tau_{2} P(t)-\left(\sigma_{5}+\alpha_{1}+\mu\right) R(t)\right)\right) .
\end{aligned}
$$

At the illicit drug use and banditry-present equilibrium, the following relations hold 
from the system (1):

$$
\begin{aligned}
\pi & =\tilde{\beta}\left(I^{* *}+\eta B^{* *}\right) S^{* *}+\mu S^{* *}, \\
\sigma_{1}+\gamma_{1}+\delta_{1}+\mu & =\frac{\tilde{\beta}\left(I^{* *}+\eta B^{* *}\right)}{I^{* *}}+\frac{\alpha_{1} R^{* *}}{I^{* *}} \\
\sigma_{2}+\gamma_{2}+\delta_{2}+\mu & =\frac{\gamma_{1} I^{* *}}{B^{* *}} \\
\sigma_{3}+\gamma_{3}+\tau_{1}+\mu & =\frac{\sigma_{1} I^{* *}+\sigma_{2} B^{* *}}{D^{* *}} \\
\sigma_{4}+\tau_{2}+\delta_{4}+\mu & =\frac{\gamma_{2} B^{* *}+\gamma_{3} D^{* *}}{P^{* *}} \\
\sigma_{5}+\alpha_{1}+\mu & =\frac{\tau_{1} D^{* *}+\tau_{2} P^{* *}}{R^{* *}} .
\end{aligned}
$$

Using the relations (32) in (31) and simplifying yields

$$
\begin{aligned}
\frac{d \mathfrak{F}}{d t}= & \tilde{\beta} S^{* *}\left(I^{* *}+\eta B^{* *}\right)\left(1-\frac{S^{* *}}{S}\right)+\mu S^{* *}\left(2-\frac{S}{S^{* *}}-\frac{S^{* *}}{S}\right)+\alpha_{1} R^{* *}\left(1-\frac{R I^{* *}}{R^{* *} I}\right) \\
& +\tilde{\beta} S^{* *}(I+\eta B)\left(1-\frac{S I^{* *}}{S^{* *} I}\right)+\frac{\sigma_{1} \alpha_{1} \tau_{1} \gamma_{3}}{d_{3} d_{4} d_{5}} I^{* *}\left(2-\frac{I B^{* *}}{I^{* *} B}-\frac{I D^{* *}}{I^{* *} D}\right) \\
& +\left(d_{1}+\tilde{\beta} S^{* *}\right)\left(1-\frac{I B^{* *}}{I^{* *} B}\right)+\frac{\sigma_{1} \alpha_{1} \tau_{1}}{d_{3} d_{5}} I^{* *}\left(2-\frac{I B^{* *}}{I^{* *} B}-\frac{I D^{* *}}{I^{* *} D}\right) \\
+ & \frac{\sigma_{2} \alpha_{1} \tau_{1}}{d_{3} d_{5}} B^{* *}\left(1-\frac{B D^{* *}}{B^{* *} D}\right)+\frac{\sigma_{2} \alpha_{1} \tau_{1} \gamma_{3}}{d_{3} d_{4} d_{5}} B^{* *}\left(1-\frac{B D^{* *}}{B^{* *} D}\right)+\frac{\gamma_{2} \alpha_{1} \tau_{1}}{d_{4} d_{5}} B^{* *}\left(1-\frac{B P^{* *}}{B^{* *} P}\right) \\
+ & \frac{\gamma_{3} \alpha_{1} \tau_{1}}{d_{4} d_{5}} D^{* *}\left(1-\frac{D P^{* *}}{D^{* *} P}\right)+\frac{\alpha_{1} \tau_{1}}{d_{5}} D^{* *}\left(1-\frac{D R^{* *}}{D^{* *} R}\right)+\frac{\alpha_{1} \tau_{2}}{d_{5}} P^{* *}\left(1-\frac{P R^{* *}}{P^{* *} R}\right) .
\end{aligned}
$$

Since $D R^{* *} \leq D^{* *} R, D P^{* *} \leq D^{* *} P$ and $P R^{* *} \leq P^{* *} R$ then $1-\frac{D^{* *} R}{D R^{* *}} \leq 0,1-\frac{D^{* *} P}{D P^{* *}} \leq 0$ and $1-\frac{P^{* *} R}{P R^{* *}} \leq 0$ with equality if $D^{* *} R=D R^{* *}, D^{* *} P=D P^{* *}$ and $P^{* *} R=P R^{* *}$. 
Consequently, (33) becomes

$$
\begin{aligned}
\frac{d \mathfrak{F}}{d t}= & \tilde{\beta} S^{* *}\left(I^{* *}+\eta B^{* *}\right)\left(1-\frac{S^{* *}}{S}\right)+\mu S^{* *}\left(2-\frac{S}{S^{* *}}-\frac{S^{* *}}{S}\right)+\alpha_{1} R^{* *}\left(1-\frac{R I^{* *}}{R^{* *} I}\right) \\
& +\tilde{\beta} S^{* *}(I+\eta B)\left(1-\frac{S I^{* *}}{S^{* *} I}\right)+\frac{\sigma_{1} \alpha_{1} \tau_{1} \gamma_{3}}{d_{3} d_{4} d_{5}} I^{* *}\left(2-\frac{I B^{* *}}{I^{* *} B}-\frac{I D^{* *}}{I^{* *} D}\right)\left(1+\frac{\gamma_{3}}{d_{4}}\right) \\
& +\left(d_{1}+\tilde{\beta} S^{* *}\right)\left(1-\frac{I B^{* *}}{I^{* *} B}\right)+\frac{\sigma_{2} \alpha_{1} \tau_{1}}{d_{3} d_{5}} B^{* *}\left(1-\frac{B D^{* *}}{B^{* *} D}\right)\left(1+\frac{\gamma_{3}}{d_{4}}\right) \\
& +\frac{\gamma_{2} \alpha_{1} \tau_{1}}{d_{4} d_{5}} B^{* *}\left(1-\frac{B P^{* *}}{B^{* *} P}\right) .
\end{aligned}
$$

Using Arithmetic Mean -Geometric Mean inequality [34], the following ineqaulities hold:

$$
\begin{gathered}
\left(1-\frac{S}{S^{* *}}\right) \leq 0, \quad\left(2-\frac{S}{S^{* *}}-\frac{S^{* *}}{S}\right) \leq 0, \quad\left(2-\frac{I B^{* *}}{I^{* *} B}-\frac{I D^{* *}}{I^{* *} D}\right) \leq 0, \quad\left(1-\frac{B P^{* *}}{B^{* *} P}\right) \leq 0, \\
\left(1-\frac{R I^{* *}}{R^{* *} I}\right) \leq 0, \quad\left(1-\frac{S I^{* *}}{S^{* *} I}\right) \leq 0, \quad\left(1-\frac{I B^{* *}}{I^{* *} B}\right) \leq 0, \quad\left(1-\frac{B D^{* *}}{B^{* *} D}\right) \leq 0 .
\end{gathered}
$$

Moreover, since all the model parameters are non-negative, it follows from (34) that $\frac{d \mathfrak{F}}{d t} \leq 0$ with equality if and only if $S=S^{* *}, I=I^{* *}, B=B^{* *}, D=D^{* *}, P=P^{* *}, R=R^{* *}$. Hence, by LaSalle's invariance principle [29], $(S, I, B, D, P, R) \rightarrow \mathcal{D}_{0}$ as $t \rightarrow \infty$.

Literally Theorem 5 means that IDUB will remain, regardless of the initial sizes of illicit drug users and bandits in the population, whenever $\mathcal{R}_{0}>1$. This stability property is shown in Figure 3, where all the solutions tend to illicit drug use and banditry-present equilibrium (IDBPE). This now leads us to sensitivity analysis.

\subsection{Sensitivity Analysis}

Following the idea in $[9,10,31,35,36]$, we perform a sensitivity analysis of the model (1) in order to determine the contributory effects of the model parameters on the transmission and spread of the illicit drug and banditry menace in a population.

The normalized forward-sensitivity index of a variable, $v$, that depends differentiably on a parameter, $p$, is defined as

$$
\Upsilon_{p}^{v}=\frac{\partial v}{\partial p} \times \frac{p}{v}
$$

In particular, sensitivity indices of the basic reproduction number, $\mathcal{R}_{0}$, with respect to the model parameters are computed and the summary is given below in Table 2 .

Table 2. Sensitivity sign of each parameters of the model 


\begin{tabular}{cc}
\hline \hline Parameter & Sign \\
\hline \hline$\beta$ & Positive \\
$\alpha_{1}$ & Positive \\
$\tau_{1}$ & Positive \\
$\eta$ & Positive \\
$\delta_{4}$ & Positive \\
$\sigma_{1}$ & Negative \\
$\delta_{1}$ & Negative \\
$\mu$ & Negative \\
$\sigma_{2}$ & Negative \\
$\gamma_{2}$ & Negative \\
$\delta_{2}$ & Negative \\
$\sigma_{3}$ & Negative \\
$\gamma_{3}$ & Negative \\
$\gamma_{1}$ & Negative \\
$\sigma_{5}$ & Negative \\
\hline \hline
\end{tabular}

The sign of the sensitivity index plays a key role in determining how the parameters of the model relate to the basic reproduction number, $\mathcal{R}_{0}$, of the model.

In Table 2 , the parameters with positive sign have a direct relation on $\mathcal{R}_{0}$ while the ones with negative sensitivity sign as an inverse relation on $\mathcal{R}_{0}$. This means that increasing any parameter with positive sign will in turn increase the value of $\mathcal{R}_{0}$ (i.e the menace will persist) and the vice versa, while increasing any parameter with negative sign will in turn decrease the value of $\mathcal{R}_{0}$ (i.e the menace will fade out) and the vice versa. With sensitivity analysis, one can get insight on the appropriate intervention strategies to prevent and control the effect and spread of the IDUB in the population. It means that effect should be made to reduce the value of parameters with positive sign, in like manner, the value of parameters with negative sign must be increase at all cost.

In addition, the graphs of the IDUB model (1) are plotted, using the value of parameters in Table 3, to study the behaviour effects of detention rate of illicit drug users $\sigma_{1}$, treatment rate of individuals in rehabilitation center $\sigma_{5}$, detention rate of bandits $\sigma_{2}$, rehabilitation rate of detainee $\tau_{1}$, quitting rate of detainee $\sigma_{3}$, loss of determination of individuals in rehabilitation center $\alpha_{1}$, effective influence rate $\beta$, progression rates of illicit drug user to bandits $\gamma_{1}$ and rates at which bandits are imprisoned $\gamma_{2}$, as well as rates at which detainee are imprisoned $\gamma_{3}$ on the dynamics of the population. From Figure 4(a-e), it can be observed in that as $\sigma_{1}$ increases (decreases), the population of bandits decreases (increases), illicit drug user decreases (increases) with time while as $\sigma_{1}$ increases (decreases), the population of detainee and individuals in prison increases (decreases) with time. It shows that $\sigma_{1}$ has a positive effect on population of bandits and illicit drug users. The physical meaning of this is that as the detention rate of illicit drug users increases, the number of the illicit drug users and bandits in the population decreases. Thus, $\sigma_{1}$, is a good corrective measure that can reduce the spread of IDUB in the population. Figure 4(f) shows the result of the rehabilitation rate $\sigma_{5}$ on the individuals in rehabilitation center. As $\sigma_{5}$ increases, the population of individuals in rehabilitation center reduce accordingly. 


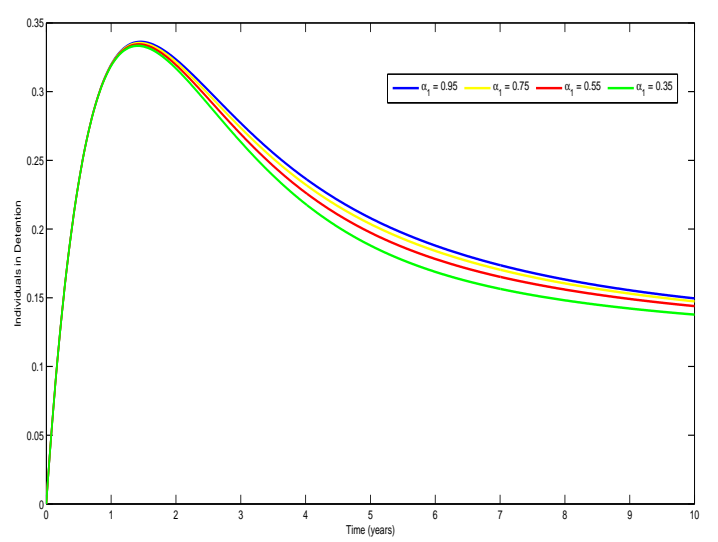

(a)

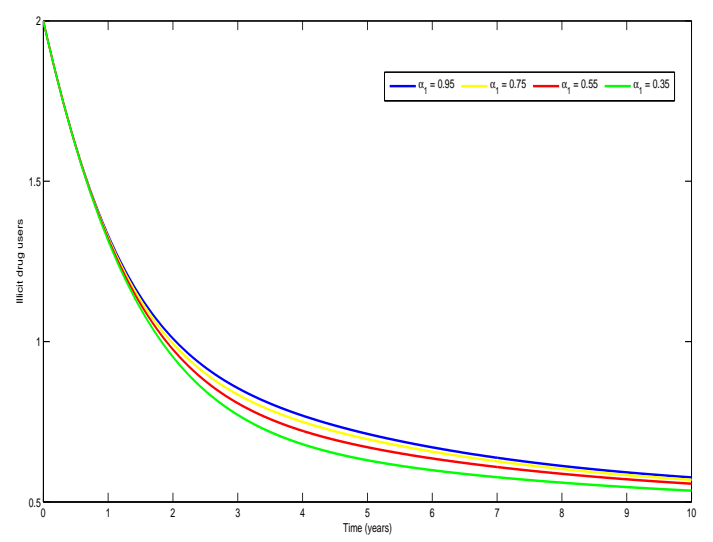

(c)

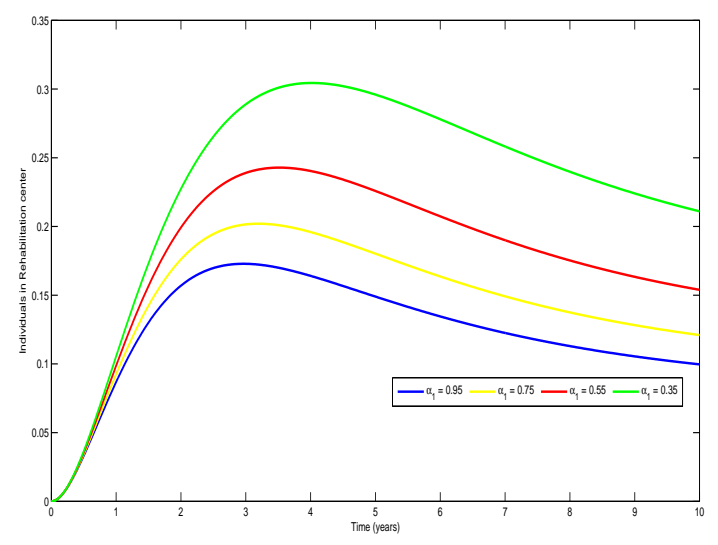

(e)

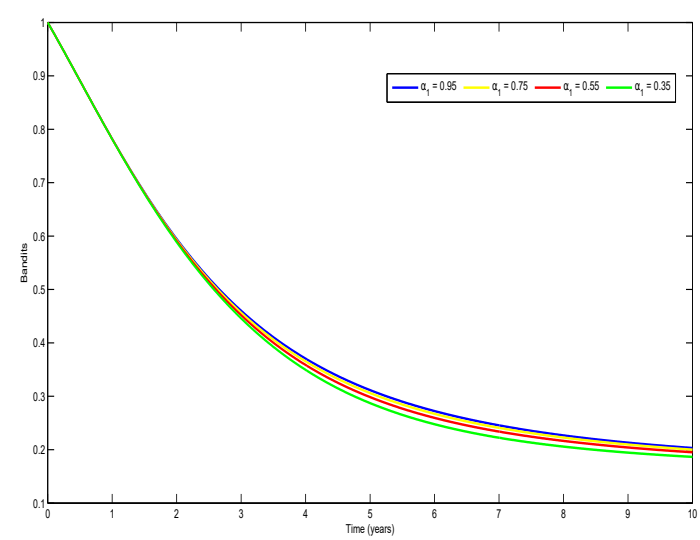

(b)

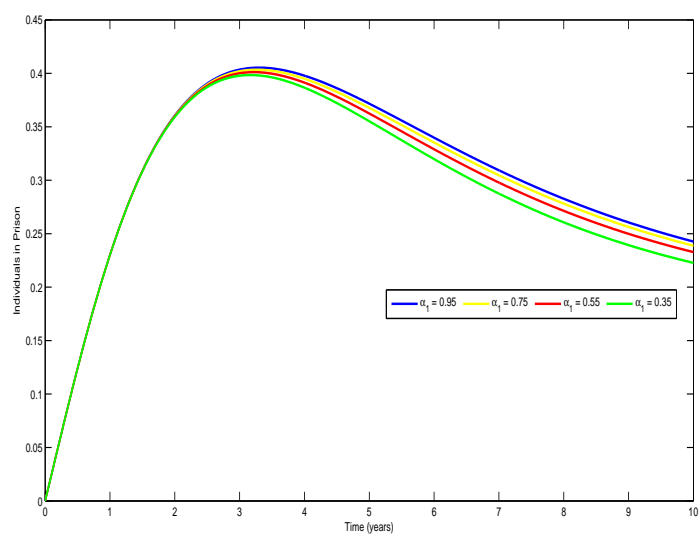

(d)

Figure 7: Simulation results of model (1) with the effect of $\alpha_{1}$ and $\tau_{1}$ on (a) Individuals in detention; (b) Bandits; (c) Illicit drug users (d) Individuals in prison and (e) Individuals in rehabilitation center. 


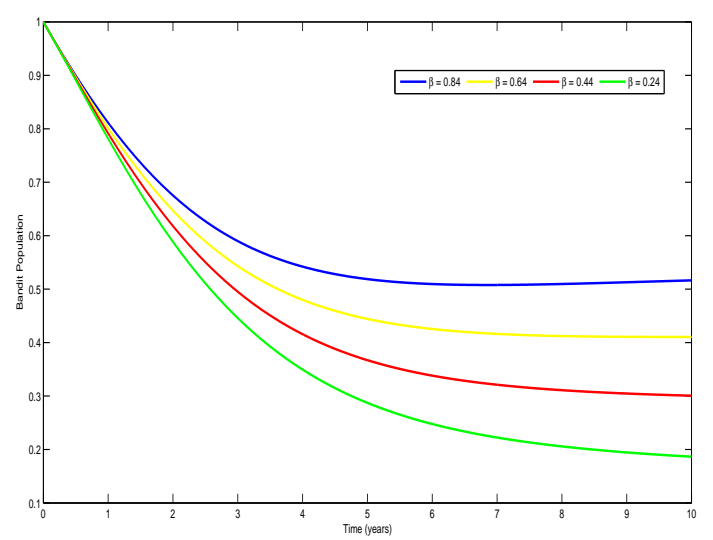

(a)

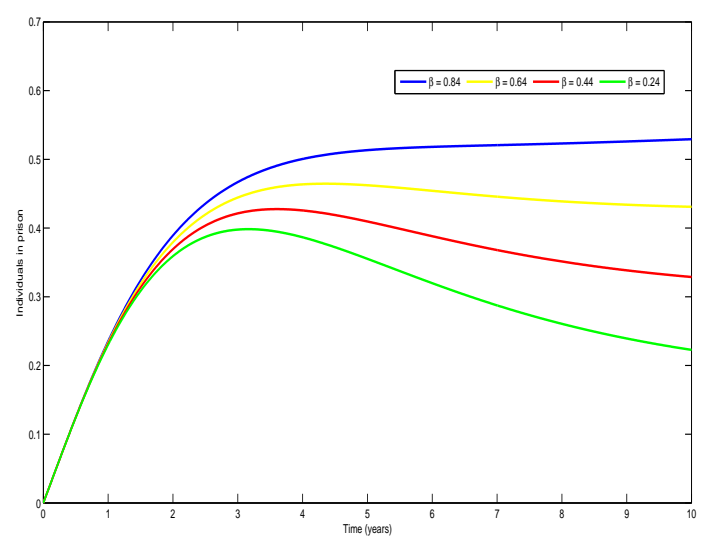

(c)

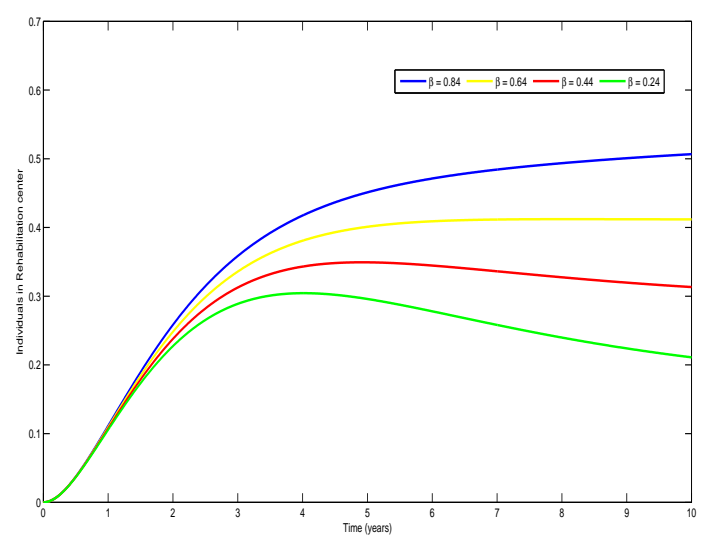

(e)

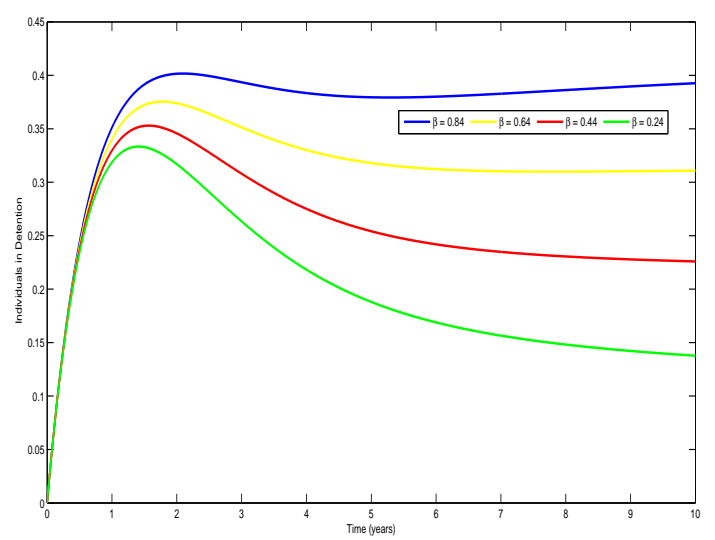

(b)

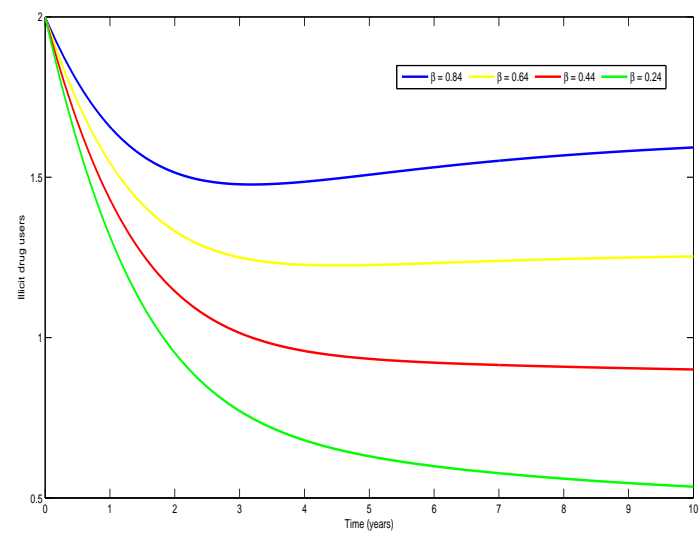

(d)

Figure 8: Simulation results of model (1) with the effect of $\beta$ on (a) Bandits; (b) Individuals in detention; (c) Individuals in prison (d) Illicit drug users and (e) Individuals in rehabilitation center. 


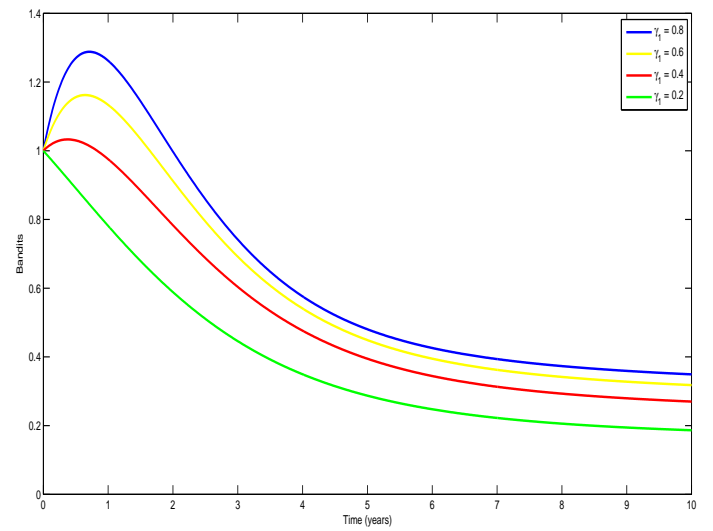

(a)

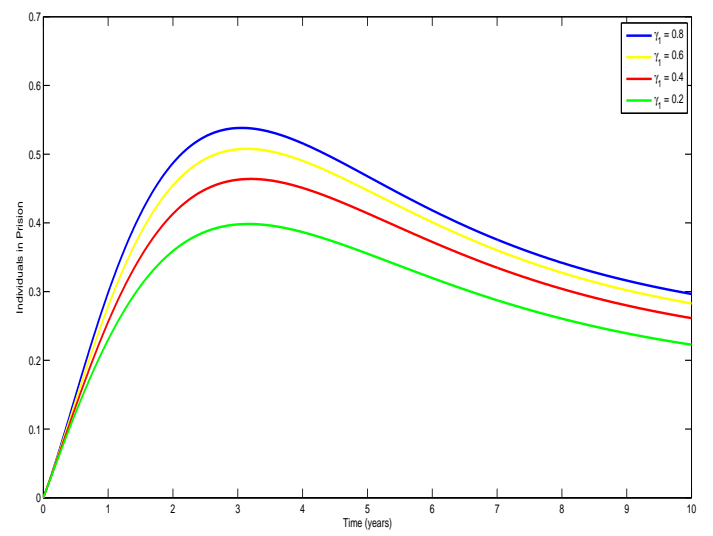

(c)

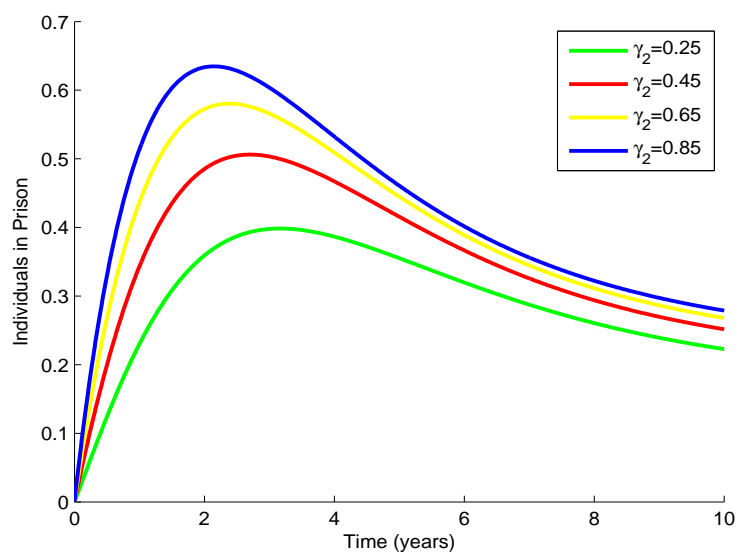

(e)

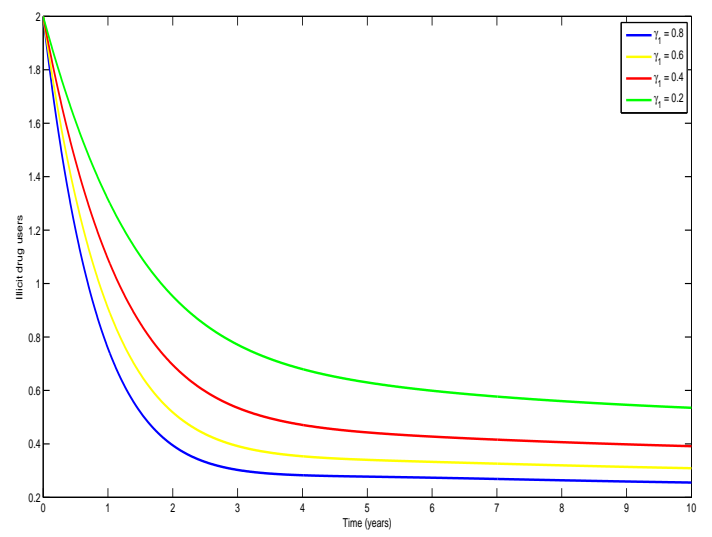

(b)

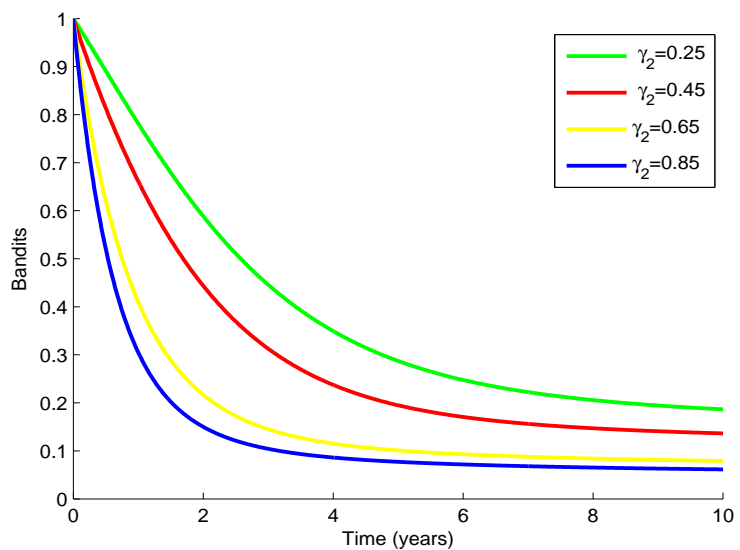

(d)

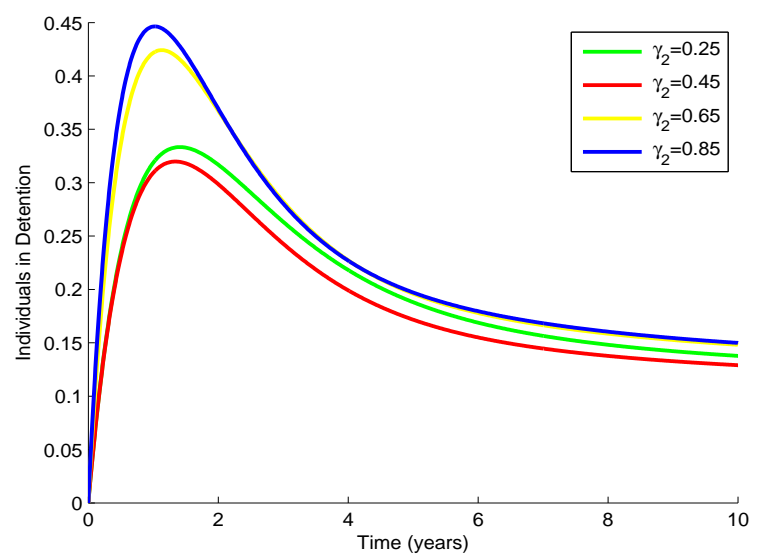

(f)

Figure 9: Simulation results of model (1) with the effect of $\gamma_{1}$ and $\gamma_{2}$ on (a) Bandits; (b) Illicit drug users (c) Individuals in prison (d) Bandits (e) Individuals in prison and (f) Individuals in detention. 


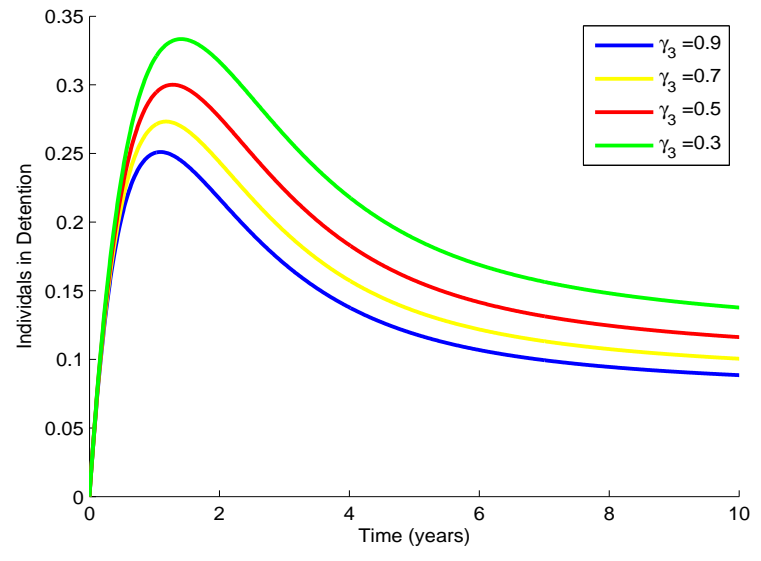

(a)

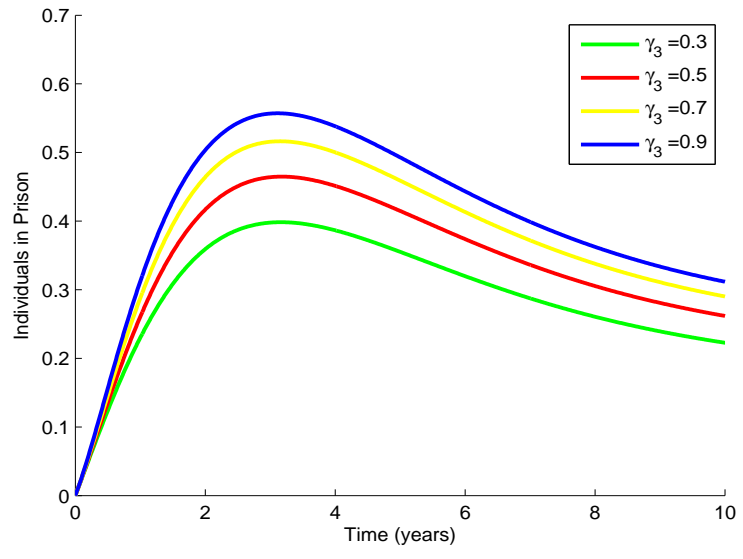

(b)

Figure 10: Simulation results of model (1) with the effect of $\gamma_{3}$ (a) Individuals in detention and (b) Individuals in prison.

Table 3. Values of parameters of the model

\begin{tabular}{cccc}
\hline \hline Parameter & Range & Baseline value & Source \\
\hline \hline$\pi$ & $40-60$ & 50 & {$[19,20]$} \\
$\beta$ & $0.2-0.5$ & 0.64 & {$[24,17]$} \\
$\eta$ & $0.6-0.9$ & 0.7 & {$[37]$} \\
$\mu$ & $0.009-0.04$ & 0.02 & {$[37]$} \\
$\alpha_{1}$ & $0.6-0.9$ & 0.75 & {$[19,38]$} \\
$\sigma_{1}$ & $0.5-0.8$ & 0.65 & {$[20,37]$} \\
$\gamma_{1}$ & $0.5-0.8$ & 0.6 & Assumed \\
$\delta_{1}$ & $0.09-0.2$ & 0.14 & {$[19]$} \\
$\sigma_{2}$ & $0.5-0.8$ & 0.6 & {$[19,37]$} \\
$\gamma_{2}$ & $0.5-0.8$ & 0.65 & {$[17]$} \\
$\delta_{2}$ & $0.09-0.2$ & 0.14 & {$[19]$} \\
$\sigma_{3}$ & $0.6-0.9$ & 0.7 & {$[17]$} \\
$\gamma_{3}$ & $0.6-0.9$ & 0.7 & {$[17]$} \\
$\tau_{1}$ & $0.7-0.95$ & 0.85 & {$[19]$} \\
$\sigma_{4}$ & $0.1-0.3$ & 0.2 & {$[17]$} \\
$\tau_{2}$ & $0.05-0.2$ & 0.1 & {$[19,4]$} \\
$\delta_{4}$ & $0.08-0.2$ & 0.14 & {$[19]$} \\
$\sigma_{5}$ & $0.4-0.9$ & 0.55 & Assumed \\
\hline \hline
\end{tabular}

In a similar manner, Figure 5(a-c) reveals the behaviour of detention rate of bandits $\sigma_{2}$ on detainees, bandits and individuals in rehabilitation center. It is observed that the populations of detainee and individuals in rehabilitation center increase (decrease) as $\sigma_{2}$ increase (decrease) but the population of bandits decreases. It shows that $\sigma_{2}$ has a positive 
effect on population of bandits. Literally, the higher the detention rate of bandits, the lesser the number of bandits in the population. This shows that $\sigma_{2}$, is also a good corrective measure that can reduce the spread of banditry in the population. Also, Figure $5(\mathrm{~d}-\mathrm{f})$ shows the effects of $\tau_{1}$ on the population of detainees, prisoners and individuals in rehabilitation center. More so, as $\tau_{1}$ rises, the populations of detainees and prisoners falls while the population of individuals in rehabilitation center increases. It shows that $\tau_{1}$ has a positive effect on populations of detainees and prisoners. Figuratively, the higher the rehabilitation rate of detainees, the lesser the number of detainees in the population which means illicit drug use and banditry will reduce. This also shows that $\tau_{1}$ is also a good corrective measure that can reduce the spread of illicit drug use and banditry in the population.

In addition, the populations of detainees, illicit drug users, prisoners and individuals in rehabilitation center increase (decrease) as quitting rate of detainees decreases (increases) (Figure 6a-d). It shows that all effort must be put in place to encourage detainee to quit the act of illicit drug use or banditry as the case may be. Literally, this means that decreasing the quitting rate of detainees, increasing the number of detainees in the population, which means illicit drug use and banditry will reduce. This also shows that $\tau_{1}$ is also a good corrective measure that can reduce the spread of IDUB in the population. In another development, Figure 7 (a-e) shows the effects of relapsed rate of individuals in rehabilitation center, $\alpha_{1}$, on the detainees, bandits, illicit drug users, prisoners and individuals in rehabilitation center. It is observed that detainees, bandits, illicit drug users and prisoners increase (decrease) as $\alpha_{1}$ increases (decreases), while the population of individuals in rehabilitation center decreases (increases). It shows that $\alpha_{1}$ has a negative effect on population of illicit drug users and bandits. The physical meaning of this is that the higher the relapsed rate of individuals in rehabilitation center, the number of illicit drug users and bandits population increases and that increasing $\alpha_{1}$ will have a positive effect on the dynamics of IDUB. This shows that rehabilitated individuals should be monitored closely to avoid relapsed or re-occurrence of IDUB in the population.

It can be observed in Figure 8(a-e) that as $\beta$ increases (decreases), the populations of bandits, detainees, prisoners, illicit drug users and individuals in rehabilitation center increase (decrease) with time. The physical meaning of this is that the bandits, detainee, prisoner, illicit drug user and individual in rehabilitation center increases as the effective influence rate of IDUB increases. This connotes that a control measures must be targeted at effective influence rate to inhibit the spread of IDUB in the population. Similarly, it is seen that the populations of bandit and prisoner increase (decrease) as the movement rate of illicit drug user to bandit increases (decreases) while as the population of illicit drug user decreases (increases) as the movement rate of illicit drug user to bandit increases (decreases) as shown in Figure 9(a-c). It shows that $\gamma_{1}$ has a positive effect on the act of illicit drug use. In physical sense, the higher the movement rate of illicit drug user to bandit, the lesser the movement of illicit drug user. Also, It is observed in Figure 9(d-f) that the population of bandit decreases (increases) as $\gamma_{2}$ increases (decreases) while the population of prisoner and detainee increase (decrease) with time. It shows that $\gamma_{2}$ has a positive effect on the population of bandit. The meaning of this is that the higher the number of movement of bandit to prison, the lesser the number of bandits in the population, but good corrective measure must be put in place in the prison so as to compliment the work of $\gamma_{2}$. This shows that increasing $\gamma_{2}$ will increase the spread of banditry in the population. 
Finally, in Figure 10(a-b), it is observed that $\gamma_{3}$ increases (decreases) as the population of detainees decreases (increases) while the population of prisoners increases (decreases). It shows that $\gamma_{3}$ has a positive effect on the population of detainees. The physical interpretation of this is that the higher the progression rate of detainees to prison, the lesser the number of detainees in the population, which means illicit drug use and banditry will reduce, but good corrective measure must be put in place in the prison so as to compliment the work of $\gamma_{3}$.

\section{Conclusion}

This work presented and analysed a suitable compartmental deterministic model for IDUB population dynamics. The illicit drug and banditry model was formulated, and analyzed to study the effect of illicit drug use and banditry on the population. The existence of illicit drug and banditry-free and illicit drug and banditry-present equilibria was determined. The illicit drug and banditry reproduction number was evaluated at illicit drug use and banditry-free equilibrium and the local stability of it was shown. The formulated model was proved to have global asymptotic stability when the illicit drug use and banditryfree equilibrium is less than unity by constructing a suitable linear Lyapunov functional. Also, the model is shown to have unique illicit drug use and banditry-present equilibrium whenever the associated illicit drug use and banditry reproduction number exceeds unity.

Further, by a suitably constructed nonlinear Lyapunov functional of Goh-Volterra type, the unique illicit drug use and banditry-present equilibrium was shown to be globally asymptotically stable. Bifurcation analysis of the mode was further carried out on the illicit drug and banditry-present equilibrium and proved the same to be forward bifurcation. The sensitivity analysis of the model was done to know the contributory effects of each parameter on the dynamic spread of the illicit drug use and banditry in the population. Finally, corrective measures like detention rate, rehabilitation and quitting rate should be beefed up so as to have illicit drug use and banditry free population. This points that, if the law against illicit drug use and banditry is strengthened and good corrective measure is put in place in the prison, it will reduce illicit drug users and bandits in the population.

\section{References}

[1] Top 10 biggest issues in the world today. Available at: https://borgenproject.org/biggest-issues-in-the-world/ [Online; accessed on June 8, 2021]

[2] T. W. Lineberry and J. M. Bostwick, Methamphetamine abuse: A perfect storm of complications. Mayo Clin. Proc. 817784 (2006). http://dx.doi.org/10.4065/81.1.77, PMid:16438482

[3] A. Plddemann, S. Dada, and C.Parry, Monitoring alcohol and substance abuse trends in South Africa. SACENDU Research brief.13(2):116 (2010). 
[4] Report of the global commission on drug policy. Available at: http://www.globalcommissionondrugs.org/wp-content/themes/gcdpv1/pdf/ Global Commission Report English.pdf. [Online; accessed on August 17, 2020].

[5] UNODC, World Drug Report, United Nation Publication Sales, 2013. Available at: https://www.unodc.org/unodc/secured/wdr/wdr2013/World Drug Report 2013. pdf. [Online; accessed on August 14, 2020]

[6] D.Nutt, L. A. King, W. Saulsbury and C. Blakemore, Development of a rational scale to assess the harm of drugs of potential misuse. The Lancet, 369 (9566) : 1047 - 1053 (2007).

[7] S. B. Karch and M.D. Filfum, Pharmacokinetics and pharmacodynamics of abused drugs. Taylor and Francis Group (2008).

[8] C. D. H. Parry, Substance abuse in South Africa: Country report focusing on young persons. Mental Health and Substance Abuse, MRC (1998).

[9] H. Z. Bajwa, A. S. Al-Turki, A. M. Dawas, M. Q. Behbehani, A. M. Al-Mutairi and S. AlMahmoud, Prevalence and factors associated with the use of illicit substances among male university students in Kuwait. Med Princ Pract. 22(5) 458643 (2013).

[10] J. O. Akanni, Asymptotic Stability Of Illicit Drug Dynamics with Banditry Compartment, Applied Mathematics and Information Sciences, An International Journal, 14 (5), 791 - 800 (2020).

[11] S. B. Karch and M. D. Filfum, Drug abuse handbook. Taylor and Francis Group. (2007).

[12] A. R. M. Schier, N. P. O. Ribeiro, J. E. C. Silva, A. C. O.Hallak, J. A. S. Crippa, A. E. Nardi and A. W. Zuardi, Cannabidiol, a Cannabis sativa constituent, as an anxiolytic drug. Brazilian Psychiatric Association, 34 : 104 - 117 (2012).

[13] N. R. Carlson, H. L.Miller, D. S. Heth, J. W. Donahoe and G. N. Martin, Psychology: The science of behaviour. (2010).

[14] Diagnostic and statistical manual of mental disorders: DSM-5, 2013. Available at: http://www.terapiacognitiva.eu/dwl/dsm5/DSM-5.pdf. [Online; accessed on August $20,2020]$

[15] A. Plddemann, C. D. H. Parry and B. Myers, Surge in Methamphetamine use in Cape Town. Drug alcohol Review, 27 : 185 - 189 (2008).

[16] C. D. H. Parry and A. Plddemann Drug policy for Methamphetamine use urgently needed. South African Medical Journal, 94 : 964 - 965.

[17] A, Plddemann, S, Dada, C., Parry, P., Cerff, A., Bhana, T.,Pereira, A. Carelsen, N., Kifleli, W., Gerber, C. Rosslee and D. Fourie, Monitoring alcohol and drug abuse trends in South Africa (July 1996- June 2008): Phase 24. SACENDU Research brief, 11:1 - 12 (2008). 
[18] A., Plddemann, S., Dada, Y., Williams, A.,Bhana, T., Pereira, A., Carelsen, N., Kitleli, W., Gerber, C., Rosslee, C. Parry and D.Fourie, Monitoring alcohol and drug abuse treatment admissions in South Africa. SACENDU Research brief, 13:2 (2013).

[19] F.Nyabadza, and L. Coetzee, A Systems Dynamic model for drug abuse and drugrelated crime in Western Cape Province of South Africa, Hindawi Computational and Mathematical Methods in Medicine, Article ID 4074197, 13 pages (2017). https://doi.org/10.1155/2017/4074197

[20] A. A. Herman, D. J. Stein, S. Seedat, S.G. Heeringa, H. Moomal and D. R. Williams, The South African Stress and Health (SASH) study: 12-month and lifetime prevalence of common mental disorders. South African Medical Journal, 99 : 339 - 344 (2009).

[21] C. D. H. Parry, A. Plddemann, A. Louw and T. Leggett, The 3-metros study of drugs and crime in South Africa: findings and policy implications. American Journal of Drug and Alcohol Abuse, 30:167 - 185 (2004).

[22] World Book Encyclopedia (2019). Vol. 22, Chicago: World Book.

[23] L. Pang, Z. Zhao, S. Liu and X. Zhang, A mathematical model approach for tobacco control in China, Applied Mathematics and Computation 259: 497509 (2015). http://dx.doi.org/10.1016/j.amc.2015.02.078.

[24] A. S. Kalula and F. Nyabadza, A theoretical model for substance abuse in the presence of treatment. South Africa Journal of Science; 108 (3/4), Art. 654, 12 pages (2012). htp://doi.org/10.4102/sajs.v108i3/4.654

[25] A Plddemann and C. D. H. Parry, Methamphetamine use and associated problems among adolescents in the Western Cape province of South Africa. MRC South Africa (2012). Available at: http://www.mrc.ac.za/policybriefs/Methamphetamine.pdf. [Online; accessed on August 13, 2020].

[26] S. Usaini, A. S.Hassan, S. M. Garba and J.M.S. Lubuma, Modelling the transmission dynamics of the Middle East Respiratory Syndrome Coronavirus (MERS$\mathrm{CoV}$ ) with latent immigrants. Journal of Interdisciplinary Mathematics (2019). DOI: 10.1080/09720502.2019.1692429.gov/pmc/articles/PMC3010753/. [Online; accessed on August 15, 2020].

[27] H.W. Hethcote, The Mathematics of Infectious Diseases, SIAM Review, 42(4): 599$653(2000)$.

[28] P. van den Driessche and J. Watmough, Reproduction numbers and sub-threshold endemic equilibria for compartmental models of disease transmission. Math. Biosci., 180: 29-48 (2002). https://doi.org/10.1016/S0025-5564(02)00108-6

[29] J.P. LaSalle, The stability of dynamical systems. Regional Conference Series in Applied Mathematics, SIAM, Philadelphia, Pa. (1976). 
[30] C. Castillo-Chavez and B., Song, Dynamical models of tuberculosis and their applications, Mathematical Biosciences and Engineering, 1, No 2, 361404 (2004).

[31] J. O. Akanni, F. O. Akinpelu, S. Olaniyi, A. T. Oladipo and A. W. Ogunsola, Modelling financial crime population dynamics: optimal control and cost-effectiveness analysis, Int. J. Dynam. Control 8, 531-544 (2020) https://doi.org/10.1007/s40435019-00572-3.

[32] D. Okuonghae, A.B. Gumel, B.O. Ikhimwin and E. Iboi, Mathematical assessment of the role of early latent infections and targeted control strategies on syphilis transmission dynamics. Acta Biotheoretica, (2018). https://doi.org/10.1007/s10441-018-9336-9

[33] O.S. Obabiyi and S. Olaniyi, Global stability analysis of malaria transmission dynamics with vigilant compartment. Electronic Journal of Differential Equations, 2019(09): 1-10 (2019).

[34] O.A.S. Karamzadeh, One-line proof of the AM-GM inequality. Mathematical Intelligencer, 33(2): 3, (2011). http://dx.doi.org/10.1007/s00283-010-9197-9

[35] N. Chitnis, J.M. Hyman and J.M. Cushing, Determining important parameters in the spread of malaria through sensitivity analysis of a mathematical model, Bulletin of Mathematical Biology, 70, 12721296 (2008).

[36] S. Olaniyi and O. S. Obabiyi, Qualitative analysis of malaria dynamics with nonlinear incidence function, Applied Mathematical Sciences, 8, No 78, 38893904 (2014)

[37] K. Peltzer, S. Ramlagan, G. Mohlala and G. Matseke, Illicit drug use trends in South Africa. Human Sciences Research Council. (2010). Available at: http://www.ncbi.nlm.nih-

[38] Drug information. Available at: http://www.lockedup.co.za/drug-information-knowyour-drugs.html. [Online; accessed on August 10, 2020]. 